(C) 2018, American Psychological Association. This paper is not the copy of record and may not exactly replicate the final, authoritative version of the article. Please do not copy or cite without authors permission. The final article will be available, upon publication, via its DOI: 10.1037/emo0000511

Effects of Vicarious Disgust Learning on the Development of Fear, Disgust and Attentional Biases in Children

\author{
Gemma Reynolds ${ }^{\mathrm{a}}$
}

Middlesex University, UK

Chris Askew ${ }^{\mathrm{b}}$

University of Surrey, UK.

\begin{abstract}
Author Note
aDepartment of Psychology, Middlesex University, United Kingdom.

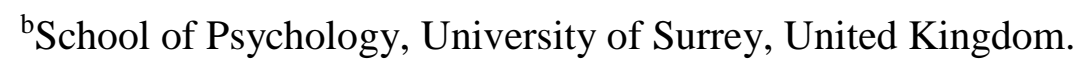

Correspondence concerning this article should be addressed to Gemma Reynolds, Department of Psychology, Middlesex University, The Burroughs, Hendon, London, NW4 4BT, United Kingdom. Email: g.reynolds@ @ mdx.ac.uk

This research did not receive any specific grant from funding agencies in the public, commercial, or not-for-profit sectors 


\begin{abstract}
Fear and disgust are defensive emotions that have evolved to protect us from harm. While fear is thought to elicit an instinctive response to deal with immediate threat, disgust elicits immediate sensory rejection to avoid contamination. One mechanism through which disgust and fear may be linked is via attentional bias towards threat. Attentional bias is a well-established feature of anxiety disorders and is known to increase following vicarious fear learning. However, the contribution of vicarious learning to the development of disgustrelated attentional biases is currently unknown. Furthermore, the influence of individual differences in disgust propensity and disgust sensitivity on fear and disgust responses has not been investigated in the context of vicarious learning. Therefore, 53 children aged 7-9 years were randomly assigned to receive either fear vicarious learning or disgust vicarious learning. Children's fear beliefs, disgust beliefs, avoidance preferences and attentional bias were measured at baseline and post-learning. Findings demonstrated increased fear and disgust responding to stimuli following disgust and fear vicarious learning. Crucially, the study provided the first evidence that disgust vicarious learning can create an attentional bias for threat in children similar to that created via fear vicarious learning. However, there was no relationship between disgust propensity and sensitivity and vicariously acquired increases in fear, disgust and attention. In conclusion, both fear and disgust vicarious learning can create attentional bias, allowing rapid detection of potentially harmful stimuli. This effect could contribute to fear development and is found even in children who are not particularly high in disgust proneness.
\end{abstract}

Keywords: disgust, fear, modelling, observational learning, vicarious learning 


\section{Effects of Vicarious Disgust Learning on the Development of Attentional Biases in}

\section{Children}

Disgust may be defined as "a type of rejection response characterized by a specific facial expression, a desire to distance oneself from the object of disgust, a physiological manifestation of mild nausea, a fear of oral incorporation of the object of disgust, and a feeling of "revulsion'” (Davey, 1994a, p. 135). It is considered an adaptive system for disease avoidance behavior, having evolved to protect from harm, disease, contamination and ingestion of dangerous or harmful substances (e.g., Cisler, Olatunji \& Lohr, 2009; Curtis, De Barra, \& Aunger, 2011; Davey, 2011; Matchett \& Davey, 1991; Oaten, Stevenson, \& Case, 2009; Rozin \& Fallon, 1987).

Disgust may have much in common with fear in that they both share the same negative valence (threat), are considered defensive emotions, have a high ability to arouse, serve parallel functions, commonly co-occur, and demonstrate several comparable ecological characteristics (Davey, 2011). Nevertheless, cognitive responses to fear and disgust are often considered distinct (e.g., Cisler, Olatunji, \& Lohr, 2009; Woody \& Teachman, 2000), in that fear elicits an instinctive and immediate response to enhance sensory acquisition so as to efficiently deal with threatening circumstances (Gray, 1987), whereas disgust is thought to elicit immediate sensory rejection functioning to diminish environmental input and therefore avoid contamination (Rozin \& Fallon, 1987; Susskind et al., 2008). Fear responding has thus been considered largely automatic compared to disgust responding which may depend on focal attention and therefore develops slower (Anderson, Christoff, Panitz, De Rosa, \& Gabrieli, 2003; Santos, Iglesias, Olivares, \& Young, 2008).

Research has indicated that disgust may be involved in the etiology and/or maintenance of anxiety disorders (see Davey \& Marzillier, 2009; Olatunji, Cisler, McKay, \& Phillips, 2010). Like fear and anxiety, the adaptive function of disgust is likely to be to 
protect the organism from harm (Davey, 1994a; Rozin \& Fallon, 1987). In the case of fear, this means protection from immediate threat, and in the case of disgust, this means protection from the harmful effects of contamination. Hence, disgust may be as much a natural defensive emotion as fear but in response to a different type of threat. However, sometimes disgust and fear may be simultaneously elicited by stimuli. Disgust has been found to be involved in a number of anxiety disorders including specific phobias such as blood-injectioninjury phobias (e.g., de Jong \& Merckelbach, 1998; Tolin, Lohr, Sawchuk, \& Lee, 1997), spider phobia (e.g., Huijding \& de Jong, 2007; Sawchuk, Lohr, Westendorf, Meunier, \& Tolin, 2002), and agoraphobia (e.g., Muris et al., 2000); as well as separation anxiety (e.g., Muris, Merckelbach, Schmidt, \& Tierney, 1999), hypochondriasis and health anxiety (e.g., Davey \& Bond, 2006), and fear of contamination in obsessive-compulsive disorder (e.g., Moretz \& McKay, 2008).

Disgust may be implicated in fear and anxiety in numerous ways. Research has demonstrated that a disgust induction can lead to greater levels of fear and anxiety in both adults (e.g., Davey, Bickerstaffe, \& MacDonald, 2006) and children (e.g., Muris, Mayer, Huijding, \& Konings, 2008), suggesting that disgust may enhance vulnerability to these emotions (Muris \& Merckelbach, 2001). However, other research has shown inconsistent results, with Marzillier and Davey (2005) demonstrating that while an anxiety induction resulted in greater levels of experienced disgust in adults, there was no equivalent influence of disgust induction on levels of reported anxiety (see also Alaoui-Ismaili, Robin, Rada, Dittmar, \& Vernet-Maury, 1997). Disgust is often acquired after direct contact with a disgust-evoking stimulus (Fallon, Rozin, \& Pliner, 1984). A number of learning mechanisms have been proposed to account for the direct association between previous disease threat and a particular stimulus (see Curtis et al., 2011), including the 'Garcia effect' (conditioned taste aversion), in which experiencing illness following ingestion of a particular food leads to an 
aversive association with the food (Garcia, Hankins, \& Rusiniak, 1974); the law of contagion, in which a neutral stimulus becomes associated with disgust after touching a stimulus considered disgusting (Rozin, Millman, \& Nemeroff, 1886); and evaluative conditioning, in which presentations of neutral stimuli together with highly disgusting stimuli leads to the neutral stimuli becoming associated with disgust (Olatunji, Forsyth, \& Cherian, 2006).

Direct learning experiences that result in an association between a previously neutral stimulus and disgust mirror explanations of fear acquisition via classical aversive conditioning (Eysenck \& Rachman, 1965; Rachman \& Costello, 1961). However, direct conditioning is not the only pathway through which fear responses can be acquired. Rachman (1977) argued that fears can also be acquired indirectly through the transmission of verbal information or vicarious learning ('observational learning' or 'modeling'). A wealth of research supports the verbal information pathway, indicating that fear-related information can increase both fear (e.g., Field \& Lawson, 2003; Field, Lawson, \& Banerjee, 2008; Field \& Schorah, 2007) and disgust (Muris et al., 2009) responses in children. Similarly, the transmission of disgust-related information to children can increase both their fear and disgust responses (Muris et al., 2008).

The second indirect pathway is vicarious learning, in which an individual develops fear of a stimulus after observing someone's fearful responses or traumatic experience with it. Vicarious learning is likely to be a crucial avoidance learning pathway because it is indirect and does not require potentially harmful direct contact with aversive stimuli before learning occurs (Rachman, 1977). Research has demonstrated that both adults (Golkar, Selbing, Flygare, Öhman, \& Olsson, 2013; Olsson et al., 2016, Olsson \& Phelps, 2004, and see Askew \& Field, 2008, for a historical review) and young infants can acquire fear responses vicariously (e.g., Dubi, Rapee, Emerton, \& Schniering, 2008; Gerull \& Rapee, 2002). Moreover, studies with 7- to 10-year-olds demonstrate that vicarious learning can lead to 
increases in fear-related cognitions (Askew \& Field, 2007; Askew, Kessock-Philip, \& Field, 2008; Askew, Reynolds, Fielding-Smith \& Field, 2016; Dunne \& Askew, 2013, in press; Dunne, Reynolds, \& Askew, 2017; Reynolds, Field, \& Askew, 2015), behavioral avoidance (Askew \& Field., 2007; Askew, Dunne, Ozdil, Reynolds, \& Field, 2013; Reynolds, Field, \& Askew, 2017) physiological responses and attentional bias (Reynolds, Field, \& Askew, 2014, 2016). Similarly, research has also shown that everyday objects paired with disgust expressions were rated as more aversive by adults compared to objects paired with neutral or happy faces (Bayliss, Frischen, Fenske, \& Tipper, 2007), and infants exposed to expressions of disgust towards a novel stimulus subsequently demonstrated reduced contact with that stimulus (Hertenstein \& Campos, 2004).

However, Muris, Mayer, Borth and Vos (2013) found that children only acquired disgust and fear beliefs for novel animals following verbal information from their mother, not from observing the mother's nonverbal facial expressions and gestures. One possible explanation may be that mothers' nonverbal expressions were both milder and less consistent than verbal information. Askew, Cakir, Poldsam and Reynolds (2014) demonstrated that when facial expressions were manipulated by the experimenter, disgust vicarious learning led to significant changes in fear beliefs and avoidance preferences with no difference between disgust and fear learning. Children also rated animals as more disgusting following both fear and disgust vicarious learning. Thus, the research suggested a bidirectional relationship between fear and disgust learning in that both disgust and fear vicarious learning affect both fear- and disgust-related responding to stimuli.

\section{Disgust, Fear and Attention}

Cognitive biases may be one mechanism through which disgust and anxiety are linked (Davey, 2011). One of the principal cognitive biases found in anxiety disorders is attentional bias towards threatening or fear-evoking stimuli in the environment (e.g., Koster, Crombez, 
Van Damme, Verschuere, \& De Houwer, 2004), especially in children and adults with high trait anxiety (e.g., Bar-Haim, Lamy, Pergamin, Bakermans-Kranenburg, \& van IJzendoorn, 2007; for reviews see Ehrenreich \& Gross, 2002; Mogg \& Bradley, 1998; Williams, Watts, MacLeod, \& Mathews, 1997). Establishing how and why attentional biases develop is critical to a full understanding of fear and anxiety, but relatively little is known about this. However, recent research with children aged 7-11 years has demonstrated that fear-related vicarious learning is one route via which attentional biases for novel animals can be learned (Reynolds et al., 2014, 2016). Given the similarities between disgust and fear, including a shared association with avoiding threat and harm (Davey, 2011), and that disgust- and fearrelated vicarious learning both increase fear beliefs and avoidance preferences (Askew et al., 2014), it is conceivable that observing someone responding to a stimulus with disgust might similarly lead to the development of an attentional bias for that stimulus.

Research supporting attentional bias towards feared stimuli has sometimes been criticised on the grounds that while the stimuli used have been considered 'threatening' or 'fear-evoking' by the researchers, they are in fact merely 'negative' or 'arousing' according to the databases and picture systems they were selected from. Indeed, many threatening images from the International Affective Picture System (IAPS: Lang, Bradley, \& Cuthbert, 2008) may actually elicit greater disgust responses than fear responses (Libkuman, Otani, Kern, Viger, \& Novak, 2007). As a result, some attentional bias findings may not be solely attributable to fear. It is also possible that there are emotion-specific attentional effects unique to fear and disgust (van Hooff, Devue, Vieweg, \& Theeuwes, 2013). Research has established attentional bias following the presentation of both disgust and fear-evoking stimuli in adults (e.g., Charash \& McKay, 2002; Ciesielski, Armstrong, Zald, \& Olatunji, 2010; Cisler, Olatunji, Lohr, \& Williams, 2009; van Hooff et al., 2013), with some research even demonstrating longer reaction times (RTs) and poorer accuracy for disgust stimuli than 
for fear stimuli (e.g., Carretié, Ruiz-Padial, López-Martín \& Albert, 2011; van Hooff et al., 2013). However, despite relatively extensive research with adults, comparable evidence with children is lacking. The contribution of direct or indirect learning to these disgust-related biases is also still unknown.

\section{Disgust Propensity and Sensitivity}

Some phobias can be predicted by individual differences in disgust propensity (the tendency to respond with disgust to disgust-eliciting stimuli) or disgust sensitivity (the tendency to appraise the experience of disgust as particularly unpleasant) (van Overveld, de Jong, Peters, Cavanagh \& Davey, 2006). Some phobias, such as fear of blood, have been found to be predicted by both disgust propensity and sensitivity; while other phobias, such as spider phobia, are better predicted by disgust sensitivity (van Overveld et al., 2006). Disgust propensity and sensitivity can lead to heightened avoidance (Hodgson \& Rachman, 1974; Matchett \& Davey, 1991), which in turn may contribute to the development or maintenance of phobias as a result of reduced familiarity and opportunities for latent inhibition or exposure (e.g., Merckelbach, de Jong, Arntz, \& Schouten, 1993).

Only a small number of studies have investigated the influence of disgust sensitivity and/or disgust propensity on attentional bias effects and these studies are limited to adult populations. For example, work by Cisler, Olatunji, Lohr, and Williams (2009) indicated that automatic attentional bias towards disgust words was found only in high disgust prone participants, whereas automatic attentional bias towards fear was present in all participants. That is, adults high in disgust propensity displayed greater difficulty in attention disengagement from disgust targets. Charash and McKay (2002) found that attentional bias towards disgust-evoking stimuli was only positively correlated with disgust sensitivity when the participants (adults) had been primed by a disgust story. Therefore, the relationship between attentional bias and disgust propensity and/or sensitivity not only remains unclear 
and limited to an adult population but is also yet to be investigated in the context of vicarious learning.

\section{Current Study}

Previous research (Askew et al., 2014) demonstrated changes in fear beliefs, disgust beliefs, and avoidance preferences in children aged 7-10 years following disgust-related vicarious learning. The current study involved children of a similar age range (7-9 years) and investigated: 1) whether disgust vicarious learning creates a stimulus-specific attentional bias in children comparable with that observed following fear vicarious learning with similar-aged children (Reynolds et al., 2014, 2016); and 2) how individual differences in disgust propensity and sensitivity influence disgust vicarious learning in children. Askew and colleagues (2014) did not measure disgust propensity and sensitivity but these traits are important in some fears (van Overveld et al., 2006). Their effects on vicarious learning are currently unknown but they may increase susceptibility to disgust learning in children.

The study addressed these questions by randomly assigning a sample of children to one of two groups: half of the children received a fear vicarious learning paradigm in which pictures of novel animals were presented alone or alongside faces expressing fear (fear vicarious learning) and half of the children received a disgust vicarious learning paradigm in which pictures of novel animals were presented alone or together with faces expressing disgust (disgust vicarious learning). Children's fear beliefs, scariness ratings, disgust beliefs, disgustingness ratings, avoidance preferences and attentional bias for the animals were measured at baseline (pre-learning) and post-learning to determine whether they had increased as a result of vicarious learning. Disgust sensitivity and propensity were also measured to establish whether they are related to fear and disgust vicarious learning. 


\section{Method}

\section{Participants}

Animal phobias most commonly develop between the ages of 5 and 9 years (Öst, 1987) which is also around the time when normal childhood developmental fears may focus on ghosts and animals (Bauer, 1976). Therefore, a typically developing (nonclinical) sample of 7 to 9-year-olds were recruited for the current study $(M=8.25$ years, $S D=9.43$ months $)$. Fifty-three children (22 boys, 31 girls) were recruited from a primary school in North London ( $n=24)$, an event held for children at a West London university, $(n=21)$, and a youth organisation in West London $(n=8)$. Participants were divided into two groups of 26 and 27 participants. Group sizes were comparable to previous vicarious learning research with children in this age group (e.g., Reynolds, Field, \& Askew, 2015). Parental consent was required for children to participate, and all children were informed that they could leave the experiment at any time without giving a reason. All children provided verbal assent to participate. The study was approved by the Middlesex University Psychology Research Ethics Committee.

\section{Materials}

Animal and face stimuli. Two Australian marsupials, a quokka and a cuscus, were used as the paired animals during vicarious learning. These animals were chosen due to their novelty to children residing in the UK and have an established track record of being used in similar studies (e.g., Askew \& Field, 2007; Reynolds et al., 2014, 2015). During the vicarious learning procedure, three pictures of each of the animals $(346 \times 444$ pixels $)$ were presented with either fearful, disgust or no faces (of the same size). The fearful and disgust faces (10 of each; 5 male, 5 female) were taken from the NimStim Face Stimulus Set (Tottenham et al., 2009). Tottenham and colleagues (2009) demonstrated that untrained 
participants accurately identified the facial expressions, with high intra-participant agreement across two testing sessions.

Disgust Propensity and Sensitivity Scale (DPSS-R). The DPSS-R (van Overveld et al., 2006) is a self-report measure consisting of eight items assessing disgust propensity (the frequency of experiencing disgust) and eight items assessing disgust sensitivity (the perceived harmful consequences and emotional impact of experiencing disgust). Children were required to rate their agreement with each item on a 5 -point Likert scale $(1=$ never to 5 $=$ always $)$. Cronbach's alphas were .66 for the Disgust Propensity scale and .73 for the Disgust Sensitivity Scale.

Fear Beliefs Questionnaires (FBQ). The FBQ (Field \& Lawson, 2003) is a selfreport assessment of children's fear cognitions towards the two animals. Example questions include 'Would you be scared if you saw a quokka/cuscus?' and 'Would you be happy to have a quokka/cuscus for a pet?' The two-animal version consists of eight items for each animal (16 in total) and children are required to respond on a 5-point Likert scale ranging from 0 to $4(0=$ no, not at all, $4=y e s$, definitely $)$. For each item, a picture of the animal is displayed in the centre of the screen with the question above and the choice of responses below. Internal consistency (Cronbach's alpha) for the questionnaire was satisfactory: at prelearning, .67 (quokka) and .69 (cuscus); and post-learning, .80 (quokka) and .80 (cuscus).

Fear Visual Analogue Scale (Fear VAS). In addition to the FBQ, how scary children believed the animals were ('scariness rating') was measured using a fear visual analogue scale. The Fear VAS consisted of a continuous horizontal line, 100mm in length, displayed on the screen, anchored by Not at All Scary at one end of the continuum and Extremely Scary at the other. Above the line was a picture of the animal in question. Children were required to use the mouse to mark on the line the point that they felt best 
represented how scary they felt each animal was and this produced a score between 0 and 100 with higher scores indicating higher fear of the animal.

Disgust Beliefs Questionnaire (DBQ). The DBQ is a modified (by Askew et al., 2014) version of Muris et al.'s (2008) self-report assessment used to measure children's disgust beliefs. Questions were modified so that they targeted the two animals. Example questions included 'Would you carefully wash your hands if you had touched a quokka/cuscus?' and 'Would you hold your nose if you were close to a quokka/cuscus?' As with the FBQ, a picture of the animal was displayed in the centre of the screen during each question with the question above and responses below. The questionnaire consists of eight items for each animal (16 in total) and children responded on a 5-point Likert scale ranging from 0 (no, not at all) to 4 (yes, definitely). Internal consistency was high: at prelearning, .76 (quokka) and .81 (cuscus); and post-learning, 86 (quokka) and .87 (cuscus).

Disgust Visual Analogue Scale (Disgust VAS). The disgust VAS was used as a measure of how disgusting children felt the animals were. The format of the Disgust VAS was identical to the Fear VAS with the exception that children were required to state how disgusting they felt the animals were. Therefore, the extreme limits of the scale were Not at all disgusting (0) and Extremely disgusting (100).

Nature reserve task (NRT). The NRT (Field \& Storksen-Coulson, 2007) was used to measure children's approach-avoidance preferences. Children were presented with a rectangular board (measuring $45 \mathrm{~cm}$ x $68 \mathrm{~cm}$ ) embellished with green felt and pipe-cleaner trees positioned in the corners to depict a nature reserve. A picture of a quokka or cuscus was placed at one end of the board. Children were asked to imagine that a Lego figure represented themselves, and to place the figure on the nature reserve where they would feel comfortable in relation to the animal. The distance from the animal to the figure was measured and taken as an indication of children's avoidance preferences for the animals. 
Dot probe task. To assess children's attentional bias towards the animals, RTs were taken during an adapted version of a pictorial dot probe task (Bradley, Mogg, White, Groom, and de Bono, 1999, see also Reynolds et al., 2014, 2016) which commenced with a fixation cross appearing on the computer screen for $500 \mathrm{~ms}$. A picture of the quokka beside a picture of the cuscus were then briefly presented on the screen, one on the left and one on the right. Pictures remained on the screen for $500 \mathrm{~ms}$ before disappearing to reveal a probe (either : or ..) in the location that one of the animals had occupied. Children were required to locate the probe as quickly as possible by pressing the ' $Z$ ' on the keyboard to indicate a : probe and the ' $\mathrm{M}$ ' on the keyboard to indicate a .. probe. The probe remained on the screen until a response had been made. The procedure began with 16 practice trials with unrelated stimuli. The dot probe task itself then commenced. Two different pictures of a cuscus and two different pictures of a quokka were used, therefore making four different pairs of pictures. The position of each picture on the left or right side of the screen was counterbalanced for each picture pair, and therefore each picture pair appeared twice, with the position of the pictures being reversed. Each combination of each picture pair was repeated with the two probes (either : or ..) appearing equally on the left or right side of the screen. Finally, each trial was presented twice. Therefore, there were an equal number of congruent and incongruent trials for each animal, and each child was presented with a total of 64 test trials. RTs and accuracy for detecting the probe were automatically recorded in E-Prime.

\section{Procedure}

The experiment was predominantly an automated procedure, written in E-prime 2.0 by the first author, and lasted approximately 20 minutes. Regardless of the place of recruitment, all children completed the experiment in a quiet room that was free from distractions. The researcher remained with the child throughout the entire experiment. 
Pre-learning measures. Children first completed the automated DPSS-R, followed by the FBQ, DBQ, Fear VAS and Disgust VAS. After completion of the questionnaires, children completed the NRT followed by the dot-probe task.

Vicarious learning. Next, children were randomly allocated to one of two groups. Half the children $(n=27)$ received fear vicarious learning, and the remaining children $(n=$ 26) received disgust vicarious learning. The procedure for all children was identical, only the emotion expressed by the faces differed (fear or disgust depending on condition). Children were presented with instructions stating "You will now watch a photograph slideshow. This will show you some photographs of a quokka or a cuscus. Sometimes it will also show you a photograph of a person's reaction to the animal." The procedure then consisted of 20 picturepicture pairing trials: 10 negative pairing trials and 10 unpaired control trials. Each of the 10 negative pairing trials consisted of pictures of one animal (quokka or cuscus) presented together with a negative face displaying either fear (fear vicarious learning group) or disgust (disgust vicarious learning group). Unpaired trials consisted of 10 pictures of the second animal (cuscus or quokka) presented alone on the screen. Unpaired (no face) trials were chosen for the control condition rather than neutral face pairings because children might have learned that animals were non-threatening if they saw them together with neutral emotional faces and this would not have been an appropriate control. Trials were presented in random order with the animal always appearing on the left side of the screen, and the face (or a blank space for the unpaired animal) on the right side of screen. A single 2 s trial consisted of the animal presented alone on the screen for $1 \mathrm{~s}$ and then for a further $1 \mathrm{~s}$ together with the face. The inter-trial interval varied randomly between $2 \mathrm{~s}$ and $4 \mathrm{~s}$. The procedure was counterbalanced to ensure that half the children in each group saw cuscuses paired with negative faces and the quokka unpaired, and the other children in the group saw quokkas paired with negative faces and the cuscus unpaired. 
Post-Learning. Following vicarious learning, children completed the FBQ, DBQ, Fear VAS, Disgust VAS, NRT and dot-probe task a second time to determine whether there had been changes in measures as a result of vicarious learning.

Debrief. Children were verbally debriefed at the end of the experiment and given the opportunity to ask any questions. They were also required to complete age-appropriate worksheets about the quokka and cuscus giving correct information about the animals.

\section{Data Analysis}

Chi-square and t-test analyses were carried out to ensure there were no differences in pre-learning characteristics of the participants in the fear group compared to the disgust group. Next, three-way 2(time: pre-learning vs. post-learning) $\times 2$ (pairing type: negative paired vs. unpaired) $\times 2$ (group: fear vs disgust vicarious learning) mixed ANOVAs were carried out on the dependent variables (fear beliefs, scariness ratings, disgust beliefs, disgustingness ratings, and avoidance preferences) to investigate changes in these measures over time, before and after fear or disgust vicarious learning, for the negative paired animal compared to the unpaired animal. Initially, these analyses also included age (months) and gender; however, no significant effects were found and therefore age and gender were excluded from all further analyses.

Three-way interactions were critical for determining whether the effect of vicarious learning on children's fear responses was significantly different in the fear and disgust vicarious learning groups. Therefore, it would be necessary to break down significant interactions using simple effects analyses to establish whether learning effects were greater for fear or disgust vicarious learning. Given, that statistical nonsignificance would not be sufficient alone to indicate no difference between fear and disgust learning groups, interpretation of nonsignificant three-way interactions was supported by calculating effect sizes and Bayes factors. In contrast to standard $F$-values and $p$-values, Bayes factors can be 
calculated to determine whether there is support for the null hypotheses that vicarious learning effects were no different for the disgust and fear vicarious learning groups. Bayes factors quantify the probability of the observed data under the alternative hypothesis relative to the null hypothesis. For example, a Bayes factor of 2 indicates the data are twice as likely under the alternative hypothesis than the null hypothesis. A Bayes factor of less than 1 indicates that the null hypothesis is more probable than the alternative hypothesis, whereas a value greater than 1 indicates that the alternative hypothesis is more probable. Values of around 1 indicate data insensitivity. Where three-way interactions tested the hypothesis that there were group differences, Bayes factors were calculated for the inclusion of the three-way interaction in the model compared to when the interaction was not included using JASP (JASP Team, 2018) and default ANOVA priors. There is good evidence for the applicability of this methodology and priors (Rouder, Engelhardt, McCabe, and Morey, 2016; Rouder, Morey, Speckman, and Province, 2012; Rouder, Morey, Verhagen, Swagman, and Wagenmakers, 2017; Wagenmakers et al., 2018).

Several analyses were carried out on the dot probe reaction time data. Initially, all incorrect responses were excluded as well as RTs less than $200 \mathrm{~ms}$, which were considered so short as to be guesses (see also Britton et al., 2013; Kim, Kim \& Kim, 2016; Miloff, Savva, \& Carlbring, 2015; Reynolds et al., 2014, 2016). Log RTs were used to adjust for large outliers (see Ratcliff, 1993). In order to investigate changes in reaction times due to vicarious learning, a three-way 2(time: pre-learning vs. post-learning) $\times 2$ (pairing type: negative paired vs. unpaired $) \times 2$ (group: disgust vs fear vicarious learning) mixed ANOVA was performed on $\log$ RTs for correct responses. However, in attentional bias studies, reaction times are generally analysed at a single time point to determine whether there is evidence of attentional bias at that time. In keeping with this, two separate 2(pairing type: negative paired vs. 
unpaired) $\times 2$ (group: disgust vs fear vicarious learning) mixed ANOVAs were also performed on log RTs at pre-learning and post-learning.

Finally, correlations were conducted between changes in all fear and disgust measures for the fear and disgust-paired animals, to investigate relationships between the variables. This was followed by correlations between disgust propensity/sensitivity and changes in all fear and disgust measures for the fear and disgust-paired animals, to explore any relationship between disgust proneness and fear or disgust vicarious learning.

\section{Results}

\section{Child Characteristics Pre-Learning}

Initial analyses confirmed no significant group differences in gender (fear group: 10 males, 17 females; disgust group: 12 males, 14 females $), \chi^{2}(1, \mathrm{~N}=53)=0.45, p=.50$ or age (fear group: $M=98.74$ months, $S D=9.75$, disgust group: $M=99.23$ months, $S D=9.28$ ), $t(51)=-.19, p=.85, d=0.05$. Additionally, there were no significant differences between males and females on disgust sensitivity, $t(51)=1.62, p=.11, d=0.43$ (males: $M=12.09$, $S D=6.89$, females: $M=9.55, S D=4.57)$, or propensity, $t(51)=0.22, p=.83, d=0.06$ (males: $M=12.86, S D=5.90$, females: $M=12.55, S D=4.55$ ).

\section{Fear Responses}

FBQ. Mean fear belief scores pre-learning and post-learning for the negative paired and unpaired animals following both fear and disgust vicarious learning are displayed in Figure 1a. The graph demonstrates an increase in fear beliefs for the negative paired animal compared to the unpaired animal following both types of vicarious learning.

The mixed ANOVA performed on average fear belief scores for the two animals revealed significant main effects of time, $F(1,51)=4.27, p=.04, \eta^{2}{ }_{p}=.08(95 \% \mathrm{CI}$ $[.00, .24])$, and pairing type $F(1,51)=7.20, p=.01, \eta_{\mathrm{p}}^{2}=.12(95 \% \mathrm{CI}[.01, .29])$, but not of 
group. The crucial time $\times$ pairing type interaction was significant, $F(1,51)=11.76, p=.001$, $\eta_{\mathrm{p}}^{2}=.19(95 \% \mathrm{CI}[.03, .36])$, indicating significant increases in fear beliefs over time for negatively paired animals compared to unpaired animals (see Figure 1a). However, the threeway time $\times$ pairing type $\times$ group interaction was not significant, $F(1,51)=1.47, p=.23, \eta^{2} \mathrm{p}$ $=.03(95 \% \mathrm{CI}[.00, .16]), \mathrm{BF}_{10}=0.428( \pm 1.89 \%)$, showing that vicarious learning effects were no different in the disgust and fear vicarious learning groups. This suggests that negative vicarious learning significantly increased fear beliefs compared to the unpaired animal regardless of emotional face type. Nonsignificance does not necessarily indicate no difference between the fear and disgust vicarious learning groups; however, the relatively small effect size here does suggest that power is unlikely to explain this result. In addition, a Bayes factor of 0.428 was calculated for the three-way time $\times$ pairing type $\times$ group interaction compared to a model without this interaction (null model), indicating that the observed data were 2.34 times more likely under the null hypothesis than the alternative. This suggests that the type of vicarious learning children received (i.e., the group variable) did not moderate the effect of the time $\times$ pairing type interaction on fear beliefs, supporting the conclusion that the type of vicarious learning was not important here. However, Bayes factors of less than 3 show only relatively weak evidence and might therefore be better understood as an indication of insufficient sensitivity in the data to distinguish between the two options (Dienes, 2014; Wagenmakers et al., 2018).

Fear VAS. How scary children felt the animals were was measured using the fear visual analogue scale (Fear VAS). Figure 1b shows that following fear vicarious learning, how scary children felt the animals were increased for fear-paired animals and decreased for unpaired animals. However, in the disgust vicarious learning group, the scariness ratings increased for disgust-paired animals, but remained relatively unchanged for unpaired animals. 
Mixed ANOVA revealed no significant main effect of time or group, but a significant main effect of pairing type $F(1,51)=6.66, p=.01, \eta^{2}{ }_{p}=.12(95 \%$ CI $[.01, .28])$. The critical time $\times$ pairing type interaction was also significant, $F(1,51)=5.04, p=.03, \eta^{2} \mathrm{p}=.09(95 \%$ CI $[.00, .25])$, showing that children's scariness ratings increased significantly for negatively paired animals compared to unpaired animals. The time $\times$ pairing type $\times$ group interaction was not significant, $F(1,51)=1.66, p=.20, \eta^{2}{ }_{p}=.03(95 \%$ CI $[.00, .17]), \mathrm{BF}_{10}=0.456( \pm$ $1.26 \%$ ), indicating no difference in learning effects for fear compared to disgust vicarious learning. The effect size for this interaction was small and the Bayes factor comparing the inclusion and exclusion of the time $\times$ pairing type $\times$ group interaction in the model indicated that the data were 2.19 times more likely under the null hypothesis (without the three-way interaction) than under the alternative hypothesis (with the three-way interaction). However, this was not quite high enough to establish unequivocal evidence for the null. Therefore, overall, we can say that the results showed negative vicarious learning increased how scary children felt the animals were, with no evidence that effects for fear and disgust vicarious learning were different.

\section{Disgust Responses}

Disgust beliefs. Figure 2a shows the mean disgust belief scores for the negative paired and unpaired animals before and after vicarious learning, showing increases in disgust beliefs for negative paired animals following both fear and disgust vicarious learning, and decreases in disgust beliefs for the unpaired animal.

Mixed ANOVA showed no significant main effects of time, pairing type, or group. However, the key time $\times$ pairing type interaction was significant, $F(1,51)=6.56, p=.01, \eta^{2} \mathrm{p}$ $=.11(95 \% \mathrm{CI}[.00, .28])$ indicating that disgust beliefs significantly increased over time for negative paired animals compared to unpaired animals. This effect of vicarious learning was no different for the fear vicarious learning and disgust vicarious learning groups, as indicated 
by a nonsignificant time $\times$ pairing type $\times$ group interaction, $F(1,51)=0.09, p=.77, \eta^{2} \mathrm{p}$ $=.002(95 \% \mathrm{CI}[.00, .07]), \mathrm{BF}_{10}=0.274( \pm 2.72 \%)$. In further support of this finding, the Bayes factor indicated that the data were 3.65 times more likely under the null hypothesis than the alternative. This represents moderate evidence (Wagenmakers et al., 2018) that vicarious learning effects, demonstrated by the significant pairing $\times$ time interaction, were not moderated by the type of vicarious learning children received (group variable). Overall then, the results showed vicarious learning of disgust beliefs and evidence that this effect was the same for emotional disgust and fear faces.

Disgust VAS. Mixed ANOVA found significant main effects of time, $F(1,51)=8.36$, $p=.006, \eta_{\mathrm{p}}^{2}=.14(95 \% \mathrm{CI}[.01, .31])$, and pairing type, $F(1,51)=7.49, p=.009, \eta_{\mathrm{p}}^{2}=.13$ $(95 \%$ CI $[.01, .30])$, but not of group. The time $\times$ pairing type, $F(1,51)=0.76, p=.38, \eta^{2}$ p $=.02(95 \% \mathrm{CI}[.00, .13])$, and time $\times$ pairing type $\times$ group interactions, $F(1,51)=0.06, p$ $=.81, \eta_{\mathrm{p}}^{2}=.001(95 \% \mathrm{CI}[.00, .05]), \mathrm{BF}_{10}=0.263( \pm 3.66 \%)$, were also nonsignificant. Therefore, there were no significant changes in how disgusting children felt the animals were for fear- and disgust-paired animals compared to unpaired animals. There was no difference between groups, confirmed by the Bayes Factor indicating the data were 3.80 times more probable under the null hypothesis than the alternative. Figure $2 \mathrm{~b}$ suggests that although disgust increased for negatively-paired animals after vicarious learning, disgust also increased for the unpaired animal, particularly in the disgust vicarious learning group.

\section{Avoidance Preferences}

The mean distance children placed their figure from the negative paired and unpaired animals in the nature reserve task at each time point is displayed in Figure 3. The graph shows that children's avoidance increased for negative paired animals and decreased for unpaired animals from pre-learning to post-learning. This was the case for both groups but was especially pronounced in the disgust vicarious learning group. 
Mixed ANOVA performed on distance scores revealed a significant main effect of pairing type, $F(1,51)=9.89, p=.003, \eta_{\mathrm{p}}^{2}=.16(95 \% \mathrm{CI}[.02, .34])$, but not time or group. The critical time $\times$ pairing type interaction was significant, $F(1,51)=9.50, p=.003, \eta^{2}=.16$ (95\% CI $[0.02,0.33])$. Therefore, avoidance preferences significantly increased from prelearning to post-learning for negatively paired animals compared to unpaired animals. This vicarious learning effect was no different for fear- and disgust-paired animals, indicated by a nonsignificant time $\times$ pairing type $\times$ group interaction, $F(1,51)=1.84, p=.18, \eta^{2}{ }_{p}=.04$ $(95 \%$ CI $[.00, .17]), \mathrm{BF}_{10}=0.421( \pm 4.05 \%)$. The Bayes factor showed that the observed data were 2.38 times more likely under the null hypothesis than the alternative. Therefore, overall, there was evidence that both fear and disgust vicarious learning increased children's avoidance preferences, with no evidence that one type of learning was more effective than the other.

\section{Attentional Bias}

Four children's data were not used because they did not follow the instructions. For the fear vicarious learning group, the percentage of incorrect responses for the negative paired animal pre- and post-learning were $2.25 \%$, and $1.62 \%$ respectively and $1.44 \%$ and $2.00 \%$ for the unpaired animal. In the disgust vicarious learning group, the percentage of incorrect responses for the negative paired animal pre- and post-learning were $2.25 \%$ and $2.88 \%$ respectively and $2.31 \%$ and $2.56 \%$ for the unpaired animal. A three-way 2(time: prelearning vs. post-learning) $\times 2$ (pairing type: negative paired vs. unpaired $) \times 2$ (group: disgust vs fear vicarious learning) mixed ANOVA performed on incorrect responses found no significant main effects or interactions.

Table 1 displays the dot probe RTs and log transformed RTs before and after learning for negative paired and unpaired animals in each learning group. The means show that children had shorter RTs for both negative paired and unpaired animals following both fear 
and disgust vicarious learning, compared to pre-learning RTs. This was confirmed by the three-way mixed ANOVA analysis on correct responses showing significant main effects of time, $F(1,47)=32.51, p<.001, \eta_{\mathrm{p}}^{2}=.41(95 \% \mathrm{CI}[.19, .56])$ and pairing type, $F(1,47)=$ $4.65, p=.036, \eta_{\mathrm{p}}^{2}=.09(95 \% \mathrm{CI}[.00, .11])$ but a nonsignificant main effect of group. The crucial time $\times$ pairing type interaction was significant, $F(1,47)=6.06, p=.018, \eta^{2}=.11$ (95\% CI $[.00, .29])$. Therefore, post-learning compared to pre-learning, RTs were significantly shorter for the negative paired animal compared to the unpaired animal. This vicarious learning effect on RTs was no different in the two groups, indicated by a nonsignificant time $\times$ pairing type $\times$ group interaction, $F(1,47)=0.41, p=.53, \eta^{2} \mathrm{p}=.009$ $(95 \%$ CI $[.00, .12]), \mathrm{BF}_{10}=0.299( \pm 0.86 \%)$, with very low effect size. In addition, the Bayes factor comparing the model with and without inclusion of the three-way interaction indicated that the data were 3.34 times more probable under the null hypothesis than the alternative. This represents moderate evidence that the type of vicarious learning did not influence levels of changes in reaction times due to vicarious learning. Thus, overall the analysis showed a significant decrease in reaction times for animals after children had seen them in a negative vicarious learning procedure, with evidence that this effect was no different for fear and disgust vicarious learning.

Further analyses were also conducted pre-learning and post-learning to investigate attentional bias at each time point. The pre-learning mixed ANOVA revealed a nonsignificant effect of group and the more theoretically important pairing type effect, $F(1$, $47)<0.01 p=.96, \eta^{2}<.001(95 \%$ CI $[.00, .003])$, indicating no evidence of attentional bias and negligible effect size. There was also a nonsignificant pairing type $\times$ group interaction, $F(1,47)=0.35, p=.56, \eta_{\mathrm{p}}^{2}=.007(95 \%$ CI $[.00, .12]), \mathrm{BF}_{10}=0.239( \pm 6.4 \%)$. The Bayes factor comparing inclusion of the pairing type $\times$ group interaction to a model without the interaction (null) indicated the data were 4.18 times more likely under the null hypothesis 
than the alternative; evidence that there was no difference in attentional bias before vicarious learning. Therefore, at baseline, there was no evidence of attentional bias, and this was the same for children in both the fear and disgust vicarious learning groups.

Post-learning results showed no significant effect of group but a significant main effect of pairing type, $F(1,47)=6.89 p=.01, \eta^{2}=.13(95 \%$ CI $[.01, .31])$. That is, regardless of whether children received fear or disgust vicarious learning, log RTs were significantly faster for the negative paired animal compared to the unpaired animal (see Table 1), even allowing for multiple tests performed on the data. However, the pairing type $\times$ group interaction was nonsignificant, $F(1,47)=0.13, p=.72, \eta^{2}{ }_{\mathrm{p}}=.003(95 \%$ CI $[.00, .09])$, $\mathrm{BF}_{10}=0.30( \pm 0.47 \%)$, which suggests no group differences in attentional bias. The Bayes factor supported this, showing that the data were 3.33 time more likely under the null than the alternative hypothesis. Overall, this means that children showed a significant post-vicarious learning attentional bias for negative-paired animals compared to unpaired animals. Evidence indicated that there was no difference in attentional bias for children who had seen fear faces during vicarious learning compared to children who saw disgust faces.

\section{Correlations Between Variables}

Fear and disgust measures. All correlations between change over time scores for the fear and disgust-paired animals are presented in Table 2. There was a significant negative correlation between changes in how scary children felt the animals were and changes in RTs for fear-paired animals, $r(25)=-.48, p=.01$, showing that as scariness increased, RTs were faster for fear-paired animals. There was also a significant positive correlation between changes in avoidance preferences and changes in fear beliefs for fear-paired animals, $r(27)$ $=.62, p<.001$; as fear beliefs for fear-paired animals increased, so did avoidance preferences. For disgust-paired animals, there was a significant correlation between how disgusting children felt the animals were and how scary they felt the animals were, $r(26)$ 
$=.46, p=.02$ : as disgustingness ratings increased, scariness ratings also increased. All remaining correlations were nonsignificant (see Table 2).

Disgust propensity and sensitivity. Overall, scores on the disgust propensity scale ranged from 0 to $24(M=12.68, S D=5.10)$ and scores on the disgust sensitivity scale ranged from 0 to $27(M=10.60, S D=5.73)$. For children in the fear vicarious learning group, scores on the disgust propensity scale ranged from 2 to $24(M=13.85, S D=4.94)$ and scores on the disgust sensitivity scale overall ranged from 3 to $27(M=10.07, S D=4.98)$. In the disgust vicarious learning group, scores on the disgust propensity scale ranged from 0 to 24 ( $M=$ $11.46, S D=5.07)$ and scores on the disgust sensitivity scale overall ranged from 0 to $25(M=$ $11.15, S D=6.46)$. Correlational analyses demonstrated that with the exception of the expected relationship between disgust propensity and disgust sensitivity (fear vicarious learning group: $r(27)=.76, p<.001$; disgust vicarious learning group: $r(26)=.73, p<.001$ ), all correlations for disgust propensity and sensitivity with changes in fear beliefs, disgust beliefs, Fear VAS scores, Disgust VAS scores, avoidance preferences and log transformed RTs were nonsignificant for both fear and disgust-paired animals.

\section{Discussion}

The current study presents a prospective experimental paradigm investigating changes to fear and disgust responses following two types of vicarious learning: fear and disgust vicarious learning. While there is a growing body of research exploring the effects of fear vicarious learning in children (e.g., Askew et al., 2008; Askew et al., 2016; Dubi et al., 2008; Dunne \& Askew, 2013; Gerull \& Rapee, 2002; Reynolds et al., 2014, 2015), disgust vicarious learning in children has rarely been investigated (Askew et al., 2014). The experiment replicated findings demonstrating increases in fear responses following fear vicarious learning (e.g., Askew \& Field, 2007; Dunne \& Askew, 2013; Reynolds et al., 
2014), and research showing increases in disgust responses following fear vicarious learning (Askew et al., 2014). The results also confirmed Askew et al.'s (2014) findings that disgust vicarious learning significantly increases (1) fear cognitions (FBQ) and how scary children felt the animals were (Fear VAS); (2) disgust cognitions (DBQ); and (3) avoidance preferences (NRT). Therefore, experimental support was provided that learning via someone else's disgust responses can increase not only fear responses (Rachman 1978), but also disgust responses (Rozin \& Fallon, 1987) for stimuli. Both fear and disgust vicarious learning led to changes in two of the three fear response systems (verbal-cognitive and overt behavior) described by Lang (1968), and also typically used to define disgust (e.g., Woody \& Teachman, 2000). There was no evidence that effects found for disgust vicarious learning differed in magnitude to those found for fear-related vicarious learning.

Avoidance is thought to characterise both fear and disgust (Woody \& Teachman, 2000). Therefore, it was unsurprising that children showed greater fear and disgust beliefs for negative paired animals and reported that, compared to unpaired animals, they would avoid them whether they had been paired with fearful or disgusted faces. Results showing increased avoidance preferences for negatively-paired animals are also in line with theoretical models of disgust that suggest that disgust may contribute to the acquisition of fears and anxieties by facilitating avoidance in an attempt to evade disease and contamination (Matchett \& Davey, 1991). That is, many animal fears may be acquired through initially being associated with contamination or disgust-evoking characteristics, followed by cultural and familial learning processes that lead to avoidance aimed at preventing transmission of contamination and disease, and subsequently, fear acquisition (Matchett \& Davey, 1991). Contradicting previous evidence (Askew et al., 2014), there were no significant changes in how disgusting children felt the animals were on the Disgust VAS for fear- and disgustpaired animals compared to unpaired animals. Disgustingness ratings appeared to increase 
for all animals after (especially disgust) vicarious learning in the current study, suggesting a possible explanation for the apparent null finding may be that learned disgust for negativepaired animals also generalised to unpaired control animals. Generalisation may have been influenced by contamination beliefs often found in disgust.

\section{Attentional bias}

One of the central aims of the current study was to investigate whether disgust vicarious learning creates a stimulus-specific attentional bias, and whether this is comparable with learned biases detected following fear vicarious learning. The findings provided a unique and noteworthy contribution to understanding by demonstrating that disgust-related vicarious learning creates attentional bias for animals. Disgust is a known feature of many fears and phobias (e.g., Davey \& Marzillier, 2009; Olatunji, Cisler, McKay, \& Phillips, 2010). Given that attentional biases are also a central feature of many fears and phobias (e.g., Koster, Crombez, Van Damme, Verschuere, \& De Houwer, 2004), and that it is not currently known how they develop, the finding that disgust-related vicarious learning increases attentional bias towards previously neutral stimuli provides an important contribution to the literature. In addition, responses in the dot probe task are unlikely to be under as much conscious control as self-report measures of fear, providing further confidence that the findings are not merely the result of demand characteristics.

Previous research has demonstrated attentional bias following fear vicarious learning (Reynolds et al., 2014, 2016) and following the presentation of disgust-evoking stimuli (e.g., Carretié et al., 2011; Charash \& McKay, 2002; Ciesielski et al., 2010; Cisler et al., 2009; van Hooff et al., 2013) but this is the first indication that disgust vicarious learning can create attentional bias towards threat in children. No evidence was found that RTs in the dot-probe task differed depending on vicarious learning type. In fact, Bayes factors provided evidence that the vicarious learning with both fear and disgust models create the same levels of 
attentional bias. Given that attentional bias towards threat is thought to function as an early detection system for potential danger, the current findings corroborate previous research suggesting that disgust is as much a defensive emotion as is fear (e.g., Charash \& McKay, 2002). This makes sense from an evolutionary perspective because the ability to learn vicariously that a particular stimulus may be harmful, based on fear or disgust responses, offers survival advantage compared to having to directly experience a negative event with the stimulus, which might be lethal. Additionally, the ability of stimuli associated with fear and disgust to capture attention has adaptive advantages in that it permits rapid detection of potentially threatening stimuli in the environment, which can then be avoided.

Although the current study found similar attentional bias effects for fear and disgust vicarious learning, it is worth mentioning that research using alternative paradigms has not always found comparable results when participants are presented with fear and disgustevoking stimuli. Although not related to vicarious learning, Carretié and colleagues (2011), for example, found slower RTs and poorer accuracy following the presentation of disgustevoking stimuli compared to fear-evoking stimuli in a digit categorisation task. Krusemark and $\mathrm{Li}$ (2011) argue that fear and disgust orient divergent cognitive processes in line with their evolutionary purposes. That is, the attentional bias towards threat following fearevoking images is in line with the role fear plays in boosting information processing (e.g., Phelps, 2006). On the other hand, disgust-evoking images initially suppress perceptual attention followed by a sensory diversion from the source of disgust, and subsequently minimising exposure to contamination (e.g., Rozin \& Fallon, 1987). On first glance, the current findings appear to contradict this argument in that attentional bias for disgust-paired and fear-paired animals was similar. However, fear as well as disgust increased for disgustpaired animals, which may explain why these animals were attended to more quickly. 
It is also worth noting that the stimuli used in earlier research exploring attentional bias towards feared stimuli (not in the context of vicarious learning) were often problematic because although they had negative valence, they were not specifically considered to be fearrelated. The current study benefits from using established emotional face stimuli taken from the NimStim Face Stimulus Set (Tottenham et al., 2009). Consequently, we can be confident that the stimuli used in the current study accurately depicted and differentiated between fear and disgust, rather than merely being negative or threatening.

Methodologically, the current study uses a now well-established (e.g., Askew \& Field, 2007; Askew et al., 2016; Dunne \& Askew, 2013; Dunne et al., 2017; Newall, Watson, Grant, \& Richardson, 2017, Reynolds et al., 2014, 2016, 2017) and fully controlled vicarious learning laboratory paradigm, using pre-learning baseline measures and a control (unpaired) animal, ensuring that changes in fear and disgust responses could only be attributed to vicarious learning manipulations. The use of a pre-learning baseline dot-probe measure here also meant that it was possible to establish that children did not have attentional bias for animals at the beginning of the experiment. Therefore, attentional bias must have been created by vicarious learning, corroborating findings from previous fear vicarious learning research that only took post-learning measures of attentional bias (e.g., Reynolds et al., 2014, 2016).

A potential alternative explanation for the effects is that they represent some other form of learning, such as evaluative conditioning, rather than vicarious learning. That is animal CSs may either 1) become associated with children's emotional response to face USs, or 2) negative valence may simply transfer from the US to the CS. For example, adults evaluated a neutral word as disgusting after Olatunji et al. (2006) presented it together with negatively valenced images (of bodily mutilation). However, research has shown that the faces do not need to elicit fear in children for learning to occur in the current paradigm. 
Askew \& Field (2007) asked children to rate how they felt when looking at USs in the procedure and they reported that the faces did not make them feel scared. This suggests that children are not associating the animal CS with their emotional response to a negatively valenced face US, but with a cognitive representation of the visual information the faces communicate about the animal.

Alternatively, the lack of difference between the effects of fear and disgust vicarious learning may be because general negative valence or threat was directly transferred from the faces to the animals. That is, fear and disgust responses were the result of neutral animals acquiring a negative or threat valence from the faces which then increased general threatrelated responding, including attentional bias and avoidance. However, this explanation also appears unlikely. Previous research has shown that devaluing the faces (US) post-vicarious learning, by indicating to children that the model was not as scared as they first appeared, decreased learned fear-related responses for animals (CS) compared to a control group (Reynolds, Field \& Askew, 2015). Given that there had been no additional learning directly involving the CS during this phase, this indicates that vicarious learning in the paradigm must be a form of CS-US learning in which the CS is associated with a cognitive representation of the US. If negative valence had been directly transferred from the US to CS during vicarious learning, later devaluation of the US should presumably not affect fear responses for the CS.

To ensure vicarious learning, children were specifically instructed that the photographs in the vicarious learning procedure showed people reacting to the animals. Thus, children had been led to believe that the model in the pictures was displaying a specific emotional expression in response to the animal it was paired with. It is notable that this procedure is different from vicarious learning procedures often used in research with adults. Traditionally, this research has often shown participants a model undergoing a conditioning procedure. For example, Berger's (1962) adult participants observed a model apparently 
moving their arm in response to an electric shock following a buzzer. Participants continued to show a galvanic skin response when the buzzer was subsequently presented alone, indicating a vicariously learned emotional response to the buzzer. The use of this type of vicarious learning procedure would not be appropriate for young children. Moreover, it would be more adaptive from an evolutionary perspective if children can learn to avoid specific stimuli when they see someone respond with fear or disgust to them, without them having to first witness the person being actually hurt by the stimulus. There are likely to be fewer opportunities to learn via the latter route. Accordingly, few spider phobic individuals in the U.K. are likely to have witnessed someone receiving a painful or lethal bite from a snake or spider than someone acting scared of the stimuli. In line with this, previous research with monkeys (e.g., Cook \& Mineka, 1990) and infants (e.g., Gerull \& Rapee, 2002) have generated vicarious learning by presenting participants with a model reacting fearfully to a particular stimulus and this seems a more likely route to the development of fear and phobia outside the laboratory.

\section{Individual Differences in Disgust Sensitivity and Propensity}

A further aim of the current study was to determine how individual differences in disgust propensity and sensitivity influence disgust vicarious learning. The effects of such disgust proneness on vicarious learning are unknown but they may increase susceptibility to disgust learning. However, self-reported levels of disgust propensity and disgust sensitivity had no relationship with attentional bias effects, or any other changes in fear and disgust responses. This was unexpected because previous research has demonstrated that attentional bias towards disgust was only found in disgust prone participants (e.g., Cisler et al., 2009). The current study demonstrated attentional bias towards disgust-paired stimuli regardless of the level of disgust propensity or sensitivity. Cisler and colleagues used a sample of undergraduate students and hence there may be age-related differences between attentional 
bias development in the adults in that sample and the children in the current sample. Additionally, it is worth noting that only disgust propensity was measured by Cisler and colleagues, and this was measured using the Disgust Scale (Haidt, McCauley, \& Rozin, 1994). The current study used the DPSS-R (van Overveld et al., 2006) and differences in findings may reflect differences in the measures used. It might also be the case that disgust proneness across the studies differs. In the current study, children had relatively low mean levels of disgust propensity $(M=12.68, S D=5.10)$ and sensitivity $(M=10.60, S D=5.73)$ and it is possible that a larger range of higher scores was reflected in Cisler et al.'s study. Further work would be required to explore the apparent discrepancies given the differences in methodology.

Some previous research (e.g., Davey, 1994b) has revealed that females have significantly higher levels of disgust sensitivity than males, and that disgust sensitivity mediates the relationship between gender and animal fears (greater animal fears found among females compared to males). The current study found no differences in disgust sensitivity or propensity at pre-learning for boys and girls in this age group. Preliminary analyses also confirmed no influence of the gender of children (or age) on the acquisition of fear and disgust responses in either group.

Previous research (e.g., Reynolds et al., 2014) failed to find a mediating effect of trait anxiety on vicarious fear learning despite a prediction that children high in trait anxiety would show greater fear responses (e.g., Field \& Purkis, 2011). Research has argued that higher order traits like disgust sensitivity and trait anxiety, but also negative affectivity and neuroticism, overlap considerably (e.g., Craske, 1997; Muris et al., 1999; Phillips, Senior, Fahy, \& David, 1998). If disgust propensity and sensitivity are too complex to separate from general traits like trait anxiety, it is perhaps unsurprising that effects of disgust propensity and sensitivity on fear and disgust responses were not found here. Furthermore, Muris and 
colleagues (1999) demonstrated that when trait anxiety was controlled for, the relationship between disgust sensitivity and anxiety symptoms disappeared in children. Although, they also demonstrated that for specific phobias, disgust sensitivity appeared to be independent of trait anxiety. Future research should explore the influence of other such higher order traits that have been found to contribute to anxiety-based symptoms.

\section{Limitations}

The procedure used in the current study compared negative (fear or disgust) vicarious learning to a no-learning control group (the unpaired animal) involving no modelling at all. It could be argued that the fear and disgust responses found post-learning were affected by the mere presence of a social stimulus during learning. Future research could avoid this by using animals paired with neutral faces in the control condition, which would ensure that the fear/disgust-paired and control animals would differ only in terms of the type of facial expression they are paired with. However, this would potentially have the disadvantage that children learn from the neutral faces that the control animals are non-threatening.

Another potential influence on the findings was that that the gaze of the face during vicarious learning was directed forward (portrait) rather than towards the animal (profile). It was considered important to use an empirically supported set of emotional facial expressions (the NimStim Face Stimulus Set: Tottenham et al., 2009) and these typically contain forward facing faces. In order to ensure that the expression of fear is accurately conveyed, very specific and detailed guidelines need to be followed; for example, having the mouth slightly open with the corners pulled straight back and lips stretched horizontally, wide open eyes with raised eyebrows, and a wrinkled forehead (e.g., see Ekman \& Friesen, 1975; Izard, 1971). These facial depictions of fear are likely to be more difficult for children to identify in a profile photo compared to a portrait photo. 
A final potential limitation of the current study was the inability to distinguish timings for attentional engagement and disengagement. Previous research has shown greater difficulties to disengage in disgust compared to fear attentional biases (e.g., Cisler, Olatunji, Lohr, \& Williams, 2009) and that disgust stimuli hold attention at much earlier stages of perceptual processing than fear-evoking stimuli (e.g., Carretié et al., 2011; van Hooff et al., 2013). Future research could make use of, for example, eye-tracking or a rapid serial visual presentation paradigm to investigate whether there are differences in attentional engagement or disengagement for stimuli following fear and disgust vicarious learning.

\section{Implications and Conclusions}

The findings have several notable clinical implications. In particular, results could potentially inform effective prevention and intervention techniques in fear and disgust by providing more valuable information about learning mechanisms for clinicians, caregivers, and those working with children. That is, the study highlights the importance of the role of a model in influencing children's fear- and disgust-related cognitions and behavioural avoidance. Indeed, recent research has demonstrated that presenting children with positive vicarious learning immediately following a fear-related modelling event can prevent fear responses from developing (e.g., Reynolds et al., 2016; Reynolds, Wasely, Dunne, \& Askew, 2017). Furthermore, the knowledge that both fear and disgust vicarious learning can create attentional bias towards threatening stimuli, even in children not high in disgust proneness, can improve clinical and theoretical understanding of the processes involved in some fears, which could further aid clinicians in providing effective treatments for specific fears and phobias.

In summary, the current study demonstrates that, like fear vicarious learning, disgust vicarious learning during childhood can create attentional bias towards novel stimuli, allowing rapid detection of potentially harmful stimuli in the environment. Additionally, the 
results support previous research demonstrating an increase in fear cognitions, disgust beliefs and avoidance preferences following both fear and disgust vicarious learning. Crucially, there was no evidence that levels of disgust and fear responses acquired via disgust vicarious learning were any different to those acquired via fear vicarious learning. Furthermore, disgust propensity or disgust sensitivity had no influence on fear and disgust vicarious learning, suggesting that disgust vicarious learning can create attentional bias even in children who are not particularly high in disgust proneness. 


\section{Acknowledgements}

With thanks to David Wasely (Middlesex University), Cristina Ambrosio and Katrakaza Evdoxia (both Kingston University) for contributing towards data collection and entry.

\section{Key Points}

- Disgust and fear may be linked via an attentional bias towards threat

- The study explored whether fear and disgust responses and biases differ in magnitude following disgust vicarious learning compared to fear vicarious learning in children aged 7-9 years

- Results revealed that the increase in fear and disgust responding to stimuli following disgust vicarious learning was similar in magnitude to responding following fear vicarious learning, as well as demonstrating that disgust vicarious learning can create attentional bias towards threat that is comparable to biases created following fear vicarious learning

- The findings potentially inform effective prevention and intervention techniques in fear and disgust by providing valuable information about learning mechanisms 


\section{References}

Alaoui-Ismaili, O., Robin, O., Rada, H., Dittmar, A., \& Vernet-Maury, E. (1997). Basic emotions evoked by odorants: Comparison between autonomic responses and selfevaluation. Physiology and Behavior, 62, 713-720. doi: 10.1016/S00319384(97)90016-0

Anderson, A. K., Christoff, K., Panitz, D., De Rosa, E., \& Gabrieli, J. D. E. (2003). Neural correlates of the automatic processing of threat facial signals. The Journal of Neuroscience, 23, 5627-5633.

Askew, C., Cakir, K., Poldsam, L., \& Reynolds, G. (2014). The effect of disgust and fear modeling on children's disgust and fear for animals. Journal of Abnormal Psychology, 123, 566-577. doi: 10.1037/a0037228

Askew, C., Dunne, G., Özdil, Z., Reynolds, G., \& Field, A. P. (2013). Stimulus fearrelevance and the vicarious learning pathway to fear. Emotion, 13, 915-925. doi:10.1037/a0032714

Askew, C., \& Field, A. P. (2007). Vicarious learning and the development of fears during childhood. Behaviour, Research and Therapy, 45, 2616-2627. doi:10.1016/j.brat.2007.06.008

Askew, C. \& Field, A. P. (2008). The vicarious learning pathway to fear 40 years on. Clinical Psychology Review, 28, 1249-1265. doi.org/10.1016/j.cpr.2008.05.003

Askew, C., Kessock-Philip, H. \& Field, A. P. (2008). Interactions between the indirect pathways to fear in children: what happens when verbal threat information and vicarious learning combine? Behavioural and Cognitive Psychotherapy, 36, 491-505. doi: $10.1017 / \mathrm{S} 1352465808004402$ 
Askew, C., Reynolds, G., Fielding-Smith, S., \& Field, A. P. (2016). Inhibition of vicariously learned fear in children using positive modeling and prior exposure. Journal of Abnormal Psychology, 125, 279-291. doi: 10.1037/abn0000131

Bar-Haim, Y., Lamy, D., Pergamin, L., Bakermans-Kranenburg, M. J., \& van Ijzendoorn, M. H. (2007). Threat-related attentional bias in anxious and nonanxious individuals: A meta-analytic study. Psychological Bulletin, 133, 1-24. doi: 10.1037/0033-2909.133.1.1

Bauer, D. H. (1976). An exploratory study of developmental changes in children's fears. Journal of Child Psychology and Psychiatry, 17, 69-74. doi: 10.1111/j.14697610.1976.tb00375.x

Bayliss, A. P., Frischen, A., Fenske, M. J., \& Tipper, S. P. (2007). Affective evaluations of objects are influenced by observed gaze direction and emotional expression. Cognition, 104, 644-653. doi: 10.1016/j.cognition.2006.07.012

Berger, S. M. (1962). Conditioning through vicarious instigation. Psychological Review, 69, 450-466. doi.org/10.1037/h0046466

Bradley, B. P., Mogg, K., White, J., Groom, C., \& De Bono, J. (1999). Attentional bias for emotional faces in generalized anxiety disorder. British Journal of Clinical Psychology, 38, 267-278. doi:10.1348/014466599162845

Britton, J. C., Bar-Haim, Y., Clementi, M. A., et al. (2013). Training-associated changes and stability of attention bias in youth: implications for attention bias modification treatment for pediatric anxiety. Developmental Cognitive Neuroscience, 4, 52-64. doi: 10.1016/j.den.2012.11.001

Carretié, L., Ruiz-Padial, E., López-Martín, S., \& Albert, J. (2011). Decomposing unpleasantness: Differential exogenous attention to disgusting and fearful stimuli. Biological Psychology, 86, 247-253. doi: 10.1016/j.biopsycho.2010.12.005 
Charash, M., \& McKay, D. (2002). Attention bias for disgust. Anxiety Disorders, 16, 529541.

Ciesielski, B. G., Armstrong, T., Zald, D. H., \& Olatunji, B. O. (2010). Emotion modulation of visual attention: Categorical and temporal characteristics. Plos One, 5, e13860. doi: 10.1371/journal.pone.0013860

Cisler, J. M., Olatunji, B. O. \& Lohr, J. M. (2009). Disgust fear and the anxiety disorders: a critical review. Clinical Psychology Review, 29, 34-46. doi:10.1016/j.cpr.2008.09.007

Cisler, J. M., Olatunji, B. O., Lohr, J. M., \& Williams, N. L. (2009). Attentional bias differences between fear and disgust: Implications for the role of disgust in disgustrelated anxiety disorders. Cognition and Emotion, 23, 675-687. doi: 10.1080/02699930802051599.

Craske, M. G. (1997). Fear and anxiety in children and adolescents. Bulletin of the Menninger Clinic, 61, 4-36.

Curtis, V., de Barra, M., \& Aunger, R. (2011). Disgust as an adaptive system for disease avoidance behaviour. Philosophical Transactions of The Royal Society, 366, 389-401. doi: $10.1098 /$ rstb.2010.0117

Darwin, C. R. (1872). The expression of the emotions in man and animals. London: John Murray. 1st edition.

Davey, G. C. L. (1994a). Disgust. In V. S. Ramachandrian, (Ed.), Encyclopedia of human behavior (pp. 135-141). San Diego, CA: Academic Press.

Davey, G. C. L. (1994b). Self-reported fears to common indigenous animals in an adult UK population: the role of disgust sensitivity. British Journal of Psychology, 85, 541-554. doi: 10.1111/j.2044-8295.1994.tb02540.x 
Davey, G. C. L. (2011). Disgust: The disease-avoidance emotion and its dysfunctions. Philosophical Transactions of The Royal Society, 366, 3453-3465. doi: 10.1098/rstb.2011.0039

Davey, G. C. L., Bickerstaffe, S., \& MacDonald, B. A. (2006). Experienced disgust causes a negative interpretation bias: A causal role for disgust in anxious psychopathology. Behaviour Research and Therapy, 44, 1375-1384. doi: 10.1016/j.brat.2005.10.006

Davey, G. C. L., \& Bond, N. (2006). Using controlled comparisons in disgust psychopathology research: The case of disgust, hypochondriasis and health anxiety. Journal of Behavior Therapy and Experimental Psychiatry, 37, 4-15. doi: 10.1016/j.jbtep.2005.09.001

Davey, G. C. L., \& Marzillier, S. (2009). Disgust and animal phobias. In B. O. Olatunji \& D. McKay (Eds.), Disgust and its disorders. Theory, assessment, and treatment implications (pp. 169-190). Washington, DC: American Psychological Association. de Jong, P. J., \& Merckelbach, H. (1998). Blood-injection-injury phobia and fear of spiders: Domain specific individual differences in disgust sensitivity. Personality and Individual Differences, 24, 153-158. doi: 10.1016/S0191-8869(97)00178

Dienes, Z. (2014). Using Bayes to get the most out of non-significant results. Frontiers in Psycholology, 5, 781. doi: 10.3389/fpsyg.2014.00781

Dubi, K., Rapee, R. M., Emerton, J., \& Schniering, C. (2008). Maternal modeling and the acquisition of fear and avoidance in toddlers: Influence of stimulus preparedness and child temperament. Journal of Abnormal Child Psychology, 36, 499-512. doi:10.1007/s10802-007-9195-3

Dunne, G. \& Askew, C. (2013). Vicarious learning and un-learning of fear in children via mother and stranger models. Emotion, 13, 974-980. doi:10.1037/a0032994 
Dunne, G. \& Askew, C. (in press). Vicarious learning and reduction of fear in children via adult and child models. Emotion. doi: 10.1037/emo0000341

Dunne, G., Reynolds, G, \& Askew, C. (2017). Stimulus fear-relevance and the speed, magnitude, and robustness of vicariously learned fear. Behaviour Research and Therapy, 95, 1-18. doi.org/10.1016/j.brat.2017.05.002

Ehrenreich, J. T., \& Gross, A. M. (2002). Biased attentional behavior in childhood anxiety: A review of theory and current empirical investigation. Clinical Psychology Review, 22, 991-1008. doi: 10.1016/S0272-7358(01)00123-4

Eysenck, H. J., \& Rachman, S. (1965). The causes and cures of neurosis. London: Routledge. Fallon, A. E, Rozin, P., \& Pliner, P. (1984). The child's conception of food: The development of food rejections with special reference to disgust and contamination sensitivity. Child Development, 55, 566-575. doi: 10.2307/1129968

Field, A. P., \& Lawson, J. (2003). Fear information and the development of fears during childhood: Effects on implicit fear responses and behavioural avoidance. Behaviour Research and Therapy, 41, 1277-1293. doi:10.1016/S0005-7967(03)00034-2

Field, A. P., Lawson, J., \& Banerjee, R. (2008). The verbal threat information pathway to fear in children: The longitudinal effects on fear cognitions and the immediate effects on avoidance behavior. Journal of Abnormal Psychology, 117, 214-224. doi:10.1037/0021-843X.117.1.214

Field, A. P., \& Purkis, H. M. (2011). The role of learning in the etiology of child and adolescent fear and anxiety. In W. K. Silverman \& A. P. Field (Eds.), Anxiety disorders in children and adolescents: Research, assessment and intervention (2nd ed., pp. 227256). Cambridge, UK: Cambridge University Press. doi:10.1017/CBO9780511994920.012 
Field, A. P., \& Schorah, H. (2007). The negative information pathway to fear and heart rate changes in children. Journal of Child Psychology and Psychiatry, 48, 1088-1093. doi:10.1111/j.1469-7610.2007.01772.x

Field, A. P., \& Storksen-Coulson, H. (2007). The interaction of pathways to fear in childhood anxiety: A preliminary study. Behaviour Research and Therapy, 45, 3051-3059. doi:10.1016/j.brat.2007.09.001

Garcia, J., Hankins, W. G., \& Rusiniak, K. W. (1974). Behavioral regulation of the milieu interne in man and rat. Food preferences set by delayed visceral effects facilitate memory research and predator control. Science 185, 824-831. doi:10.1126/science. 185.4154 .824

Gerull, F. C., \& Rapee, R. M. (2002). Mother knows best: Effects of maternal modeling on the acquisition of fear and avoidance behaviour in toddlers. Behaviour Research and Therapy, 40, 279-287. doi:10.1016/S0005-7967(01)00013-4

Golkar, A., Selbing, I., Flygare, O., Öhman, A., \& Olsson, A. (2013). Other People as Means to a Safe End: Vicarious Extinction Blocks the Return of Learned Fear. Psychological Science, 24, 2182-2190. doi: 10.1177/0956797613489890

Gray, J. A. (1987). The psychology of fear and stress. Cambridge: Cambridge University Press.

Haidt, J., McCauley, C., \& Rozin, P. (1994). Individual differences in sensitivity to disgust: a scale sampling seven domains of disgust elicitors. Personality and Individual Differences, 16(5), 701-713. doi: 10.1016/0191-8869(94)90212-7

Hertenstein, M. J., \& Campos, J. J. (2004). The retention effects of an adult's emotional displays on infant behavior. Child Development, 75, 595-613. doi: 10.1111/j.14678624.2004.00695.x 
Hodgson, R. \& Rachman, S. (1974). Desynchrony in measures of fear. Behaviour Research and Therapy, 12, 319-326.

Huijding, J., \& de Jong, P. J. (2007). Beyond fear and disgust: The role of (automatic) contamination-related associations in spider phobia. Journal of Behavior Therapy and Experimental Psychiatry, 38, 200-211. doi:10.1016/j.jbtep.2006.10.009

JASP Team (2018). JASP (Version 0.8.6) [Computer software]

Kim, S. A., Kim, H., \& Kim, S. H. (2016). Reappraisal modulates attentional bias to angry faces. Frontiers in Psychology, 7, 1841, 1-9. doi: 10.3389/fpsyg.2016.01841

Koster, E. H. W., Crombez, G., Van Damme, S., Verschuere, B., \& De Houwer, J. (2004). Does imminent threat capture and hold attention? Emotion, 4, 312-317. doi: $10.1037 / 1528-3542.4 .3 .312$

Krusemark, E. A., \& Li, W. (2011). Do all threats work the same way? Divergent effects of fear and disgust on sensory perception and attention. Journal of Neuroscience, 31, 3429-3434. doi: 10.1523/JNEUROSCI.4394-10.2011

Lang, P. J. (1968). Fear reduction and fear behavior: Problems in treating a construct. In J. M. Schlien (Ed.), Research in psychotherapy (Vol. 3, pp. 90-102). Washington, DC: American Psychological Association. doi:10.1037/10546-004

Lang, P. J., Bradley, M. M., \& Cuthbert, B. N. (2008). International affective picture system (IAPS): Affective ratings of pictures and instruction manual. Technical Report A-8. University of Florida, Gainesville, FL.

Libkuman, T. M., Otani, H., Kern, R., Viger, S. G., \& Novak, N. (2007). Multidimensional normative ratings for the International Affective Picture System. Behavior Research Methods, 39, 326-334. doi: 10.3758/BF03193164 
Matchett, G., \& Davey, G. C. L. (1991). A test of a disease-avoidance model of animal phobias. Behaviour Research and Therapy, 29, 91-94. doi:10.1016/S00057967(09)80011-9

Marzillier, S. L., \& Davey, G. C. L. (2005). Anxiety and disgust: Evidence for a unidirectional relationship. Cognition and Emotion, 19, 729-750. doi: $10.1080 / 02699930441000436$

Merckelbach, H., de Jong, P. J., Arntz, A., \& Schouten, E. (1993). The role of evaluative learning and disgust sensitivity in the etiology and treatment of spider phobia. Advances in Behaviour Research and Therapy, 15, 243-255. doi: 10.1016/0146-6402(93)90011-P

Miloff, A., Savva, A., \& Carlbring, P. (2015). Cognitive bias measurement and social anxiety disorder: Correlating self-report data and attentional bias. Internet Interventions, 2, 227 234. doi: 10.1016/j.invent.2015.03.006

Mogg, K., \& Bradley, B. P. (1998). A cognitive-motivational analysis of anxiety. Behaviour Research and Therapy, 36, 809-848. doi: 10.1016/S0005-7967(98)00063-1

Moretz, M. W., \& McKay, D. (2008). Disgust sensitivity as a predictor of obsessivecompulsive contamination symptoms and associated cognitions. Journal of Anxiety Disorders, 22, 707-715. doi: 10.1016/j.janxdis.2007.07.004

Muris, P., Huijding, J., Mayer, B., Leemreis, W., Passchier, S., \& Bouwmeester, S. (2009). The effects of verbal disgust- and threat-related information about novel animals on disgust and fear beliefs and avoidance in children. Journal of Clinical Child and Adolescent Psychology, 38, 551-563. doi:10.1080/15374410902976379

Muris, P., Mayer, B., Borth, M., \& Vos, M. (2013). Nonverbal and verbal transmission of disgust from mothers to offspring: Effects on children's evaluation of a novel animal. Behavior Therapy, 44, 293-301. doi: 10.1016/j.beth.2012.10.002 
Muris, P., Mayer, B., Huijding, J., \& Konings, T. (2008). A dirty animal is a scary animal! Effects of disgust-related information on fear beliefs in children. Behaviour Research and Therapy, 46, 137-144. doi: 10.1016/j.brat.2007.09.005

Muris, P., \& Merckelbach, H. (2001). Specific phobias. In Anxiety disorders: An introduction to clinical management and research. Griez E. J. L., Faravelli C., Nutt D., \& Zohar D. (eds.). Chichester: UK, John Wiley \& Sons: 105-135.doi: 10.1002/0470846437.ch6

Muris, P., Merckelbach, H., Nederkoorn, S., Rassin, E., Candel, I., \& Horselenberg, R. (2000). Disgust and psychopathological symptoms in a nonclinical sample. Personality and Individual Differences, 29, 1163-1167. doi: 10.1016/S0191-8869(99)00263-9

Muris, P., Merckelbach, H., Schmidt, H., \& Tierney, S. (1999). Disgust sensitivity, trait anxiety and anxiety disorders symptoms in normal children. Behaviour Research and Therapy, 37, 953-961. doi: 10.1016/S0005-7967(99)00045-5

Newall, C., Watson, T., Grant, K., \& Richardson, R. (2017). The relative effectiveness of extinction and counter-conditioning in diminishing children's fear. Behaviour Research \& Therapy, 95, 42-49. doi.org/10.1016/j.brat.2017.05.006.

Oaten, M., Stevenson, R. J., \& Case, T. I. (2009). Disgust as a disease-avoidance mechanism. Psychological Bulletin,135, 303-321. doi: 10.1037/a0014823

Olatunji, B. O., Cisler, J., McKay, D., \& Phillips, M. L. (2010). Is disgust associated with psychopathology? Emerging research in the anxiety disorders. Psychiatry Research, 175, 1-10. doi: 10.1016/j.psychres.2009.04.00

Olatunji, B. O., Forsyth, J. P., \& Cherian, A. (2006). Evaluative differential conditioning of disgust: a sticky form of relational learning that is resistant to extinction. Journal of Anxiety Disorders, 21, 820-834. 
Olsson, A., McMahon, K., Papenberg, G., Zaki, J., Bolger, N., \& Ochsner, K. N. (2016). Vicarious Fear Learning Depends on Empathic Appraisals and Trait Empathy. Psychological Science, 27, 25-33. doi: 10.1177/0956797615604124

Olsson, A., \& Phelps, E. A. (2004). Learned fear of “unseen” faces after Pavlovian, observational, and instructed fear. Psychological Science, 15, 822-828. doi: 10.1111/j.0956-7976.2004.00762

Öst, L.-G. (1987). Age of onset in different phobias. Journal of Abnormal Psychology, 96, $223-229$.

Phelps, E. A. (2006). Emotion and cognition: Insights from studies of the human amygdala. Annual Review of Psychology, 57, 27-53. doi: 10.1146/annurev.psych.56.091103.070234

Phillips, M. L., Senior, C., Fahy, T., \& David, A. S. (1998). Disgust: the forgotten emotion of psychiatry. British Journal of Psychiatry, 172, 373-375. doi: 10.1192/bjp.172.5.373

Rachman, S. (1977). The conditioning theory of fear acquisition: A critical examination. Behaviour Research and Therapy, 15, 375-387. doi:10.1016/0005-7967(77)90041-9

Rachman, S., \& Costello, C. G. (1961). The aetiology and treatment of children's phobias: A review. American Journal of Psychiatry, 118, 97-105. doi: 10.1176/ajp.118.2.97

Ratcliff, R. (1993). Methods for dealing with reaction time outliers. Psychological Bulletin, 114, 510-532. doi:10.1037/0033-2909.114.3.510

Reynolds, G., Field, A. P., \& Askew, C. (2014). The effect of vicarious fear learning on children's heart rate responses and attentional bias for novel animals. Emotion, 14, 995-1006. doi:10.1037/a0037225

Reynolds, G., Field, A. P., \& Askew, C. (2015). Preventing the development of observationally learnt fears in children by devaluing the model's negative response. 
Journal of Abnormal Child Psychology, 43, 1355-1367. doi: 10.1007/s10802-0150004-0

Reynolds, G., Field, A. P., \& Askew, C. (in press): Reductions in Children's Vicariously Learnt Avoidance and Heart Rate Responses Using Positive Modeling. Journal of Clinical Child \& Adolescent Psychology. doi: 10.1080/15374416.2016.1138410

Reynolds, G., Field, A. P., \& Askew, C. (2017) Learning to fear a second-order stimulus following vicarious learning, Cognition and Emotion, 31, 572-579. doi: $10.1080 / 02699931.2015 .1116978$

Reynolds, G., Wasely, D., Dunne, G., \& Askew, C. (2017). A comparison of positive vicarious learning and verbal information for reducing vicariously learned fear. Cognition and Emotion, 19, 1-12. doi: 10.1080/02699931.2017.1389695.

Rouder, J. N., Engelhardt, C. R., McCabe, S., \& Morey, R. D. (2016). Model comparison in ANOVA. Psychonomic Bulletin \& Review, 23, 1779-1786. doi: 10.3758/s13423-016$1026-5$

Rouder, J. N., Morey, R. D., Speckman, P. L., \& Province, J. M. (2012). Default Bayes factors for ANOVA designs. Journal of Mathematical Psychology, 56, 356-374. doi: 10.1016/j.jmp.2012.08.001

Rouder, J. N., Morey, R. D., Verhagen, A. J., Swagman, A. R., \& Wagenmakers, E.-J. (2017). Bayesian analysis of factorial designs. Psychological Methods, 22, 304-321. doi: $10.1037 /$ met0000057

Rozin, P., \& Fallon. A. E. (1987). A perspective on disgust. Psychological Review, 94, 23-41. doi: 10.1037/0033-295X.94.1.23

Rozin, P., Millman, L., \& Nemeroff, C. (1986). Operation of the laws of sympathetic magic in disgust and other domains. Journal of Personality and Social Psychology, 50, 703712. doi: $10.1037 / 0022-3514.50 .4 .703$ 
Santos, I, M., Iglesias, J., Olivares, E. I., \& Young, A. W. (2008). Differential effects of object-based attention on evoked potentials to fearful and disgusted faces. Neuropsychologia, 46, 1468-1479. doi: 10.1016/j.neuropsychologia.2007.12.024

Sawchuk, C. N., Lohr, J. M., Westendorf, D. H., Meunier, S. A., \& Tolin, D. F. (2002). Emotional responding to fearful and disgusting stimuli in specific phobics. Behaviour Research and Therapy, 40, 1031-1046. doi: 10.1016/S0005-7967(01)00093-6

Susskind, J. M., Lee, D. H., Cusi, A., Feiman, R., Grabski, W., \& Anderson, A. K. (2008). Expressing fear enhances sensory acquisition. Nature Neuroscience, 11, 843-850. doi: $10.1038 / \mathrm{nn} .2138$

Tolin, D. F., Lohr, J. M., Sawchuk, C. N., \& Lee, T. C. (1997). Disgust and disgust sensitivity in blood-injection-injury and spider phobia. Behaviour Research and Therapy, 35, 949-953. doi: S0005-7967(97)00048-X.

Tottenham, N., Tanaka, J. W., Leon, A. C., McCarry, T., Nurse, M., Hare, T. A., .. . Nelson, C. (2009). The NimStim set of facial expressions: Judgments from untrained research participants. Psychiatry Research, 168, 242-249. doi:10.1016/j,psychres.2008.05.006

van Hooff, J. C., Devue, C., Vieweg, P. E., Theeuwes, J. (2013). Disgust- and not fearevoking images hold our attention. Acta Psychologica, 143, 1-6. doi: 10.1016/j.actpsy.2013.02.001

van Overveld, W. J. M., de Jong, P. J., Peters, M. L., Cavanagh, K., \& Davey, G. C. L. (2006). Disgust propensity and disgust sensitivity: Separate constructs that are differentially related to specific fears. Personality and Individual Differences, 41, 12411252. doi: 10.1016/j.paid.2006.04.021

Wagenmakers, E.-J., Love, J., Marsman, M., Jamil, T., Ly, A., Verhagen, J., ... Morey, R. D. (2018). Psychonomic Bulletin \& Review, 25, 58-76. 
Williams, J. M. G., Watts, F. N., MacLeod, C., \& Mathews, A. (1997). Cognitive psychology and emotional disorders (2nd ed.). Chichester: Wiley

Woody, S. R., \& Teachman, B. A. (2000). Intersection of disgust and fear: Normative and pathological views. Clinical Psychology: Science and Practice, 7, 291-311. doi: 10.1093/clipsy.7.3.291 
Dot Probe

\begin{tabular}{|c|c|c|c|c|}
\hline \multirow[b]{2}{*}{ Group } & \multirow[b]{2}{*}{ Time } & \multirow[b]{2}{*}{ Pairing } & \multirow{2}{*}{ RTs } & \\
\hline & & & & Log RTs \\
\hline \multirow[t]{4}{*}{ Fear } & Pre & Negative & $1251.65(390.28)$ & $3.08(0.14)$ \\
\hline & & Unpaired & $1255.21(383.40)$ & $3.08(0.12)$ \\
\hline & Post & Negative & $872.11(378.39)$ & $2.90(0.19)$ \\
\hline & & Unpaired & 913.65 (366.66) & $2.93(0.17)$ \\
\hline \multirow[t]{4}{*}{ Disgust } & Pre & Negative & $1105.98(370.73)$ & $3.02(0.14)$ \\
\hline & & Unpaired & $1110.12(437.42)$ & $3.02(0.15)$ \\
\hline & Post & Negative & $907.91(409.87)$ & $2.92(0.20)$ \\
\hline & & Unpaired & 976.85 (415.57) & $2.95(0.18)$ \\
\hline
\end{tabular}

Table 1. Mean (Standard Deviation) reaction times and log transformed reaction times for detecting the probe when it appeared behind the negative paired or unpaired animals at each time point (pre-learning and post-learning) following fear and disgust vicarious learning. 


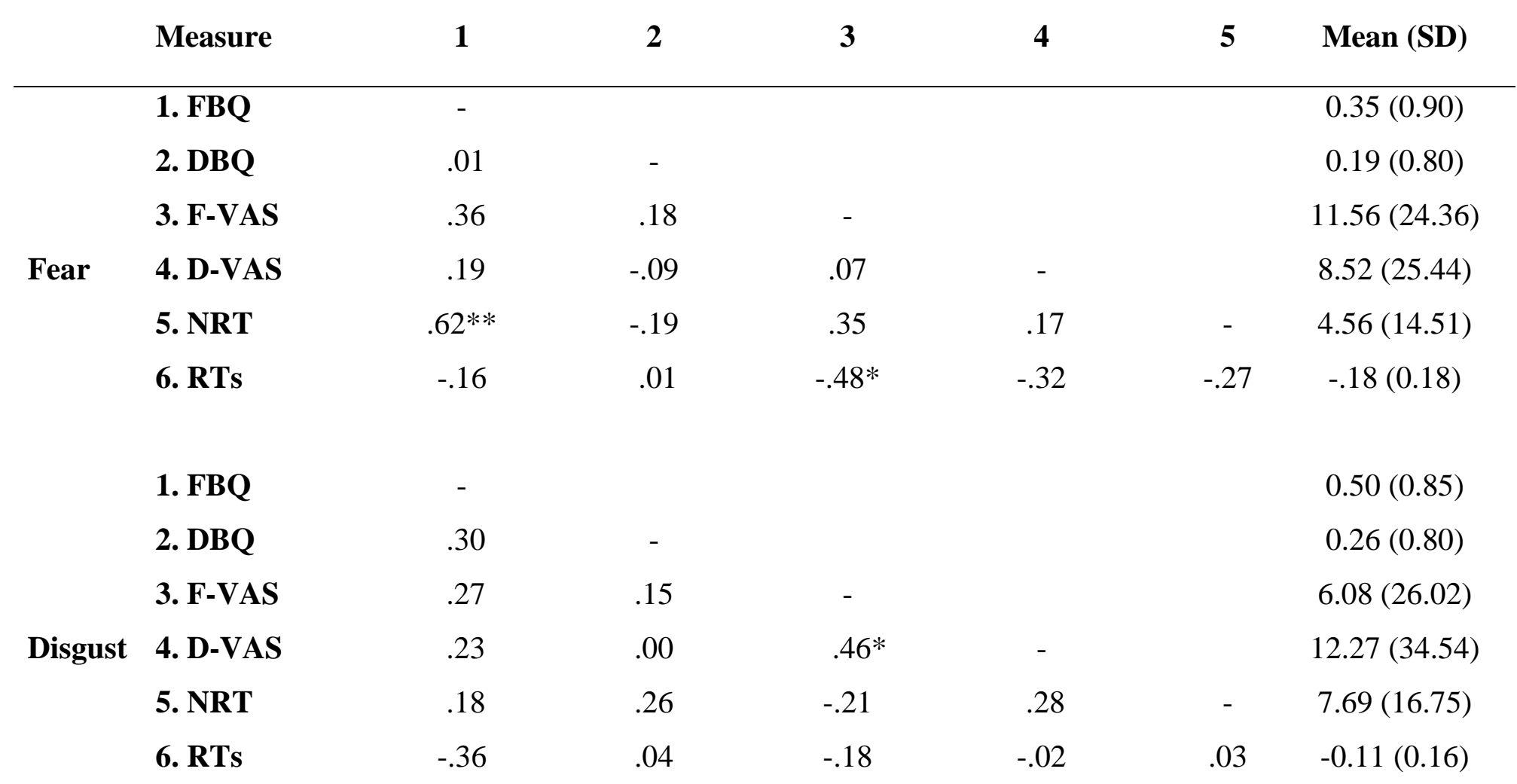

Note: FBQ=Fear Beliefs Questionnaire, DBQ=Disgust Beliefs Questionnaire, NRT=Nature Reserve Task, RTs=Reaction Times in Dot Probe $* p<.05, * * p<.01$

Table 2. Pearson correlation coefficients for changes in FBQ, DBQ, F-VAS, D-VAS, NRT and RT scores for both fear-paired and disgustpaired animals. 
Fig. 1a

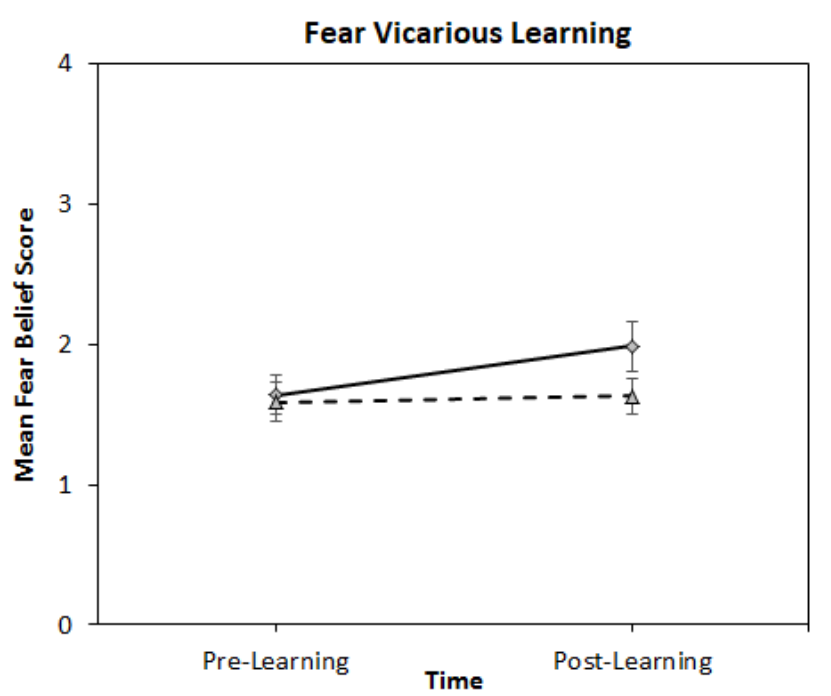

Fig. $1 b$

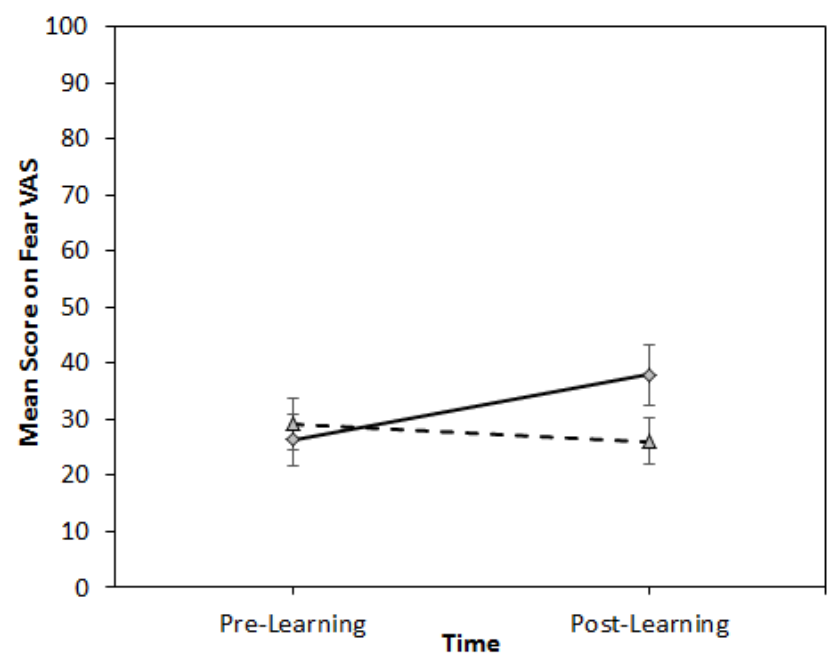

Disgust Vicarious Learning
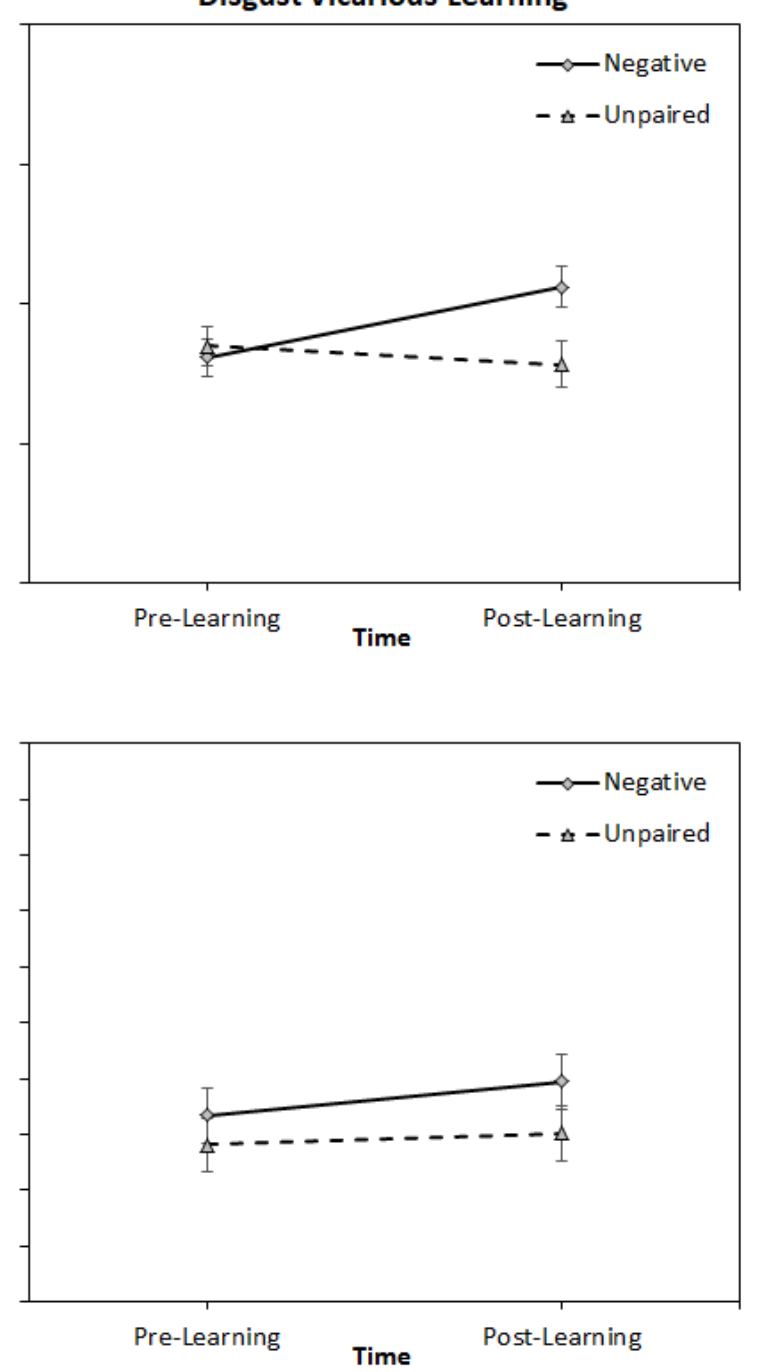

Figure 1: (a) Mean (and SE) fear belief scores for the negative paired and unpaired animals at each time point (pre-learning and post-learning) following fear and disgust vicarious learning. (b) Mean (and SE) scores on the fear VAS for the negative paired and unpaired animals at each time point (pre-learning and post-learning) following fear and disgust vicarious learning. 
Fig. 2a

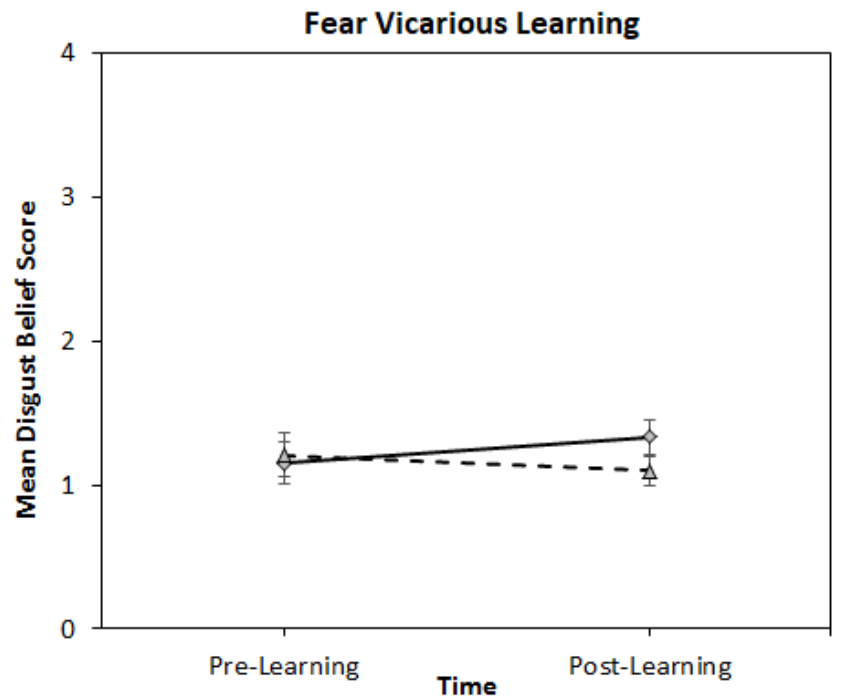

Fig. $2 b$

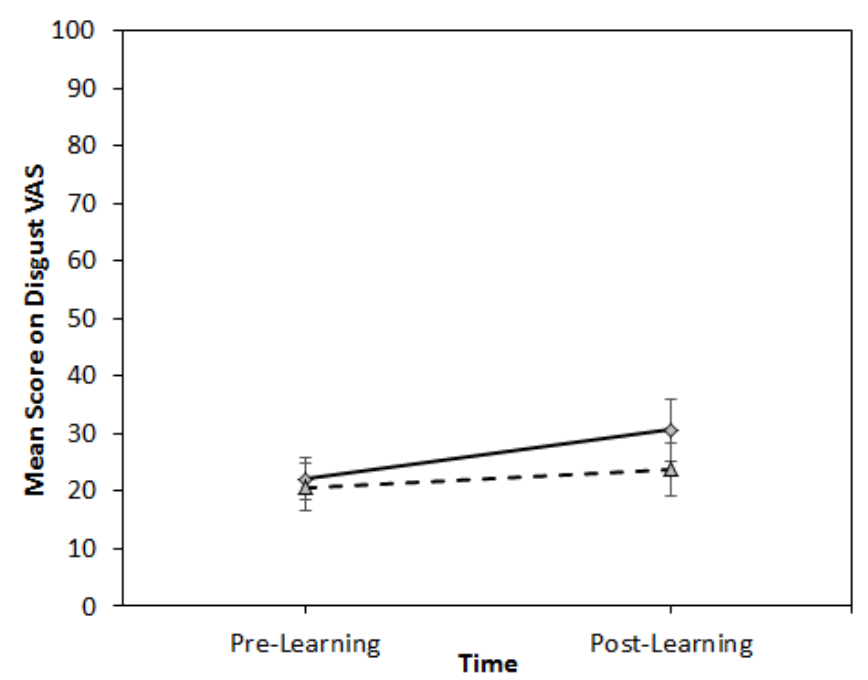

Disgust Vicarious Learning
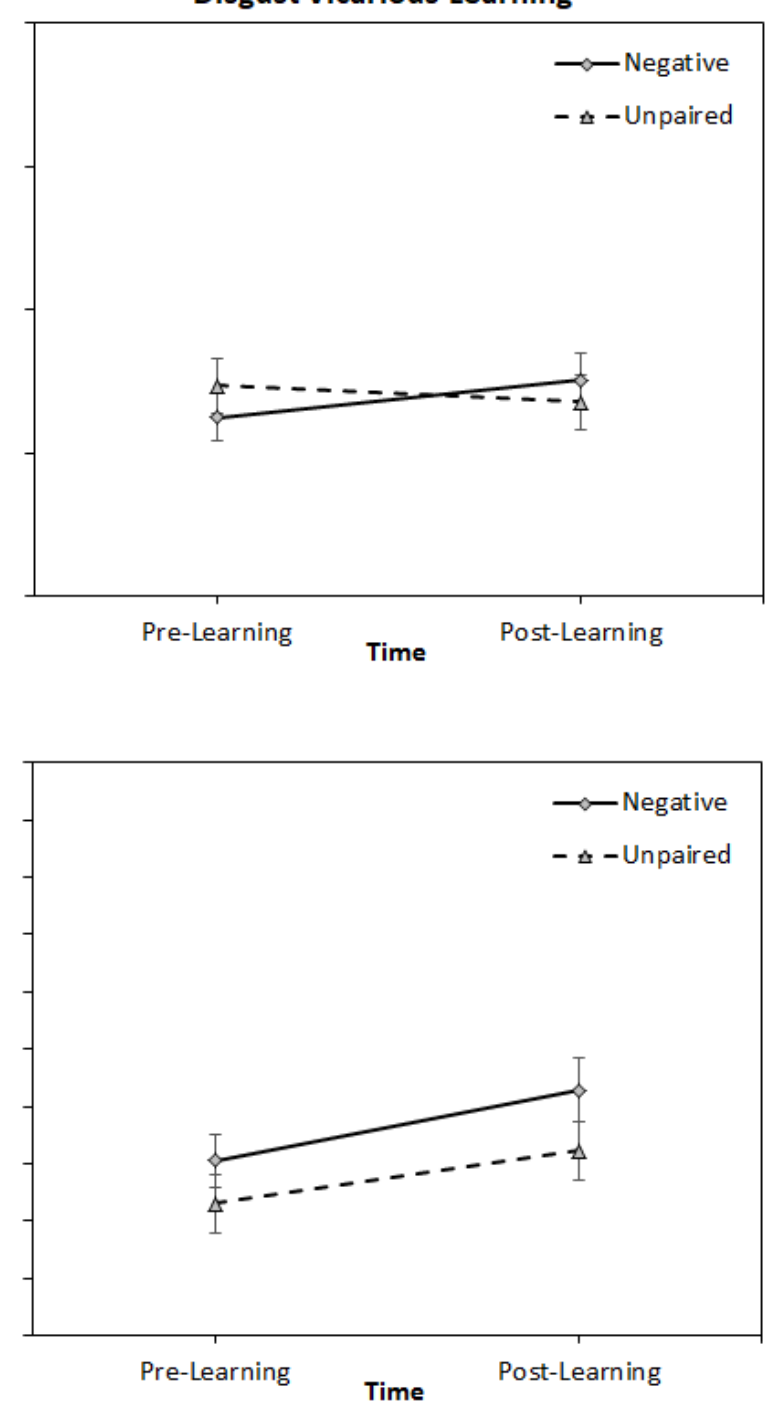

Figure 2: (a) Mean (and SE) disgust belief scores for the negative paired and unpaired animals at each time point (pre-learning and post-learning) following fear and disgust vicarious learning. (b) Mean (and SE) scores on the disgust VAS for the negative paired and unpaired animals at each time point (pre-learning and post-learning) following fear and disgust vicarious learning. 

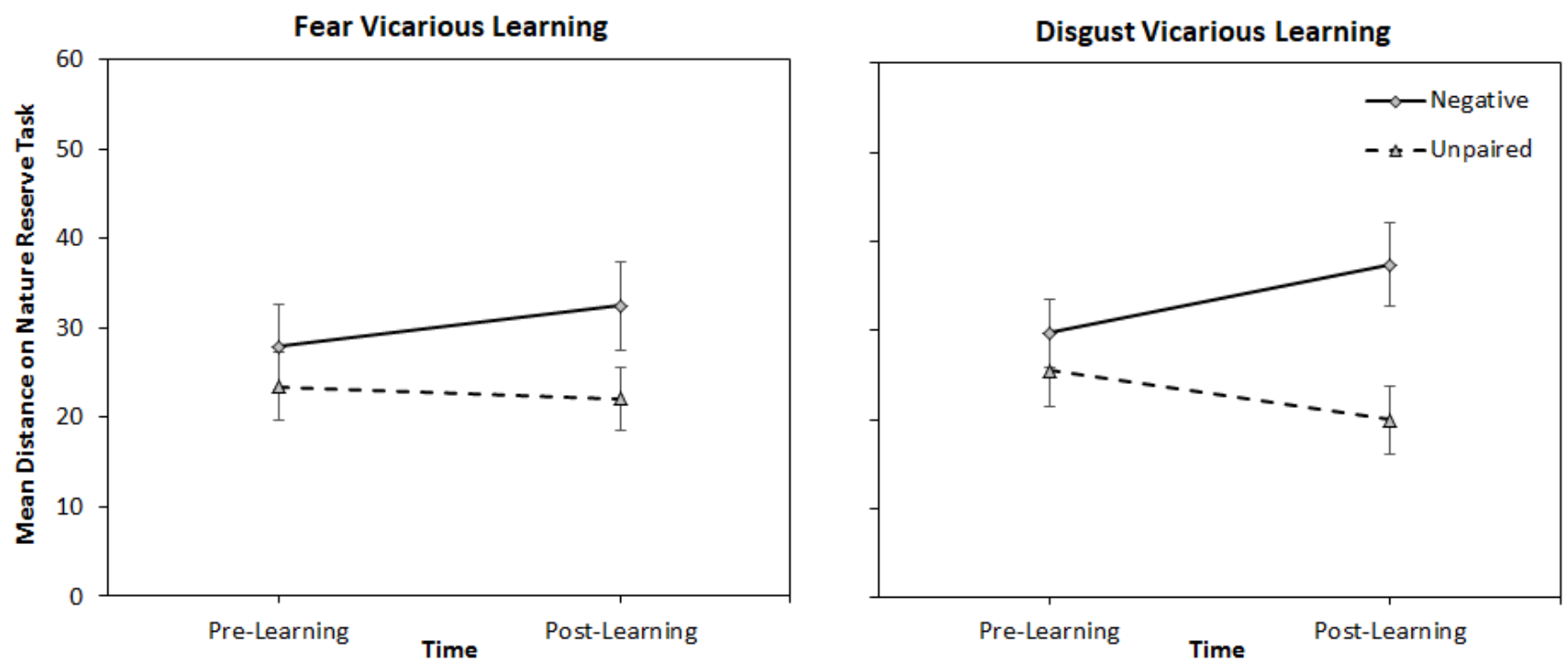

Figure 3: Mean (and SE) distance $(\mathrm{cm})$ that children placed themselves on the nature reserve task in relation to the negative paired and unpaired animals at each time point (prelearning and post-learning) following fear and disgust vicarious learning 